\title{
UICN
}

\section{Reconhecer e relatar outras medidas efetivas de conservação baseadas em área}

Grupo de Trabalho da Comissão Mundial de Áreas Protegidas sobre OMECs
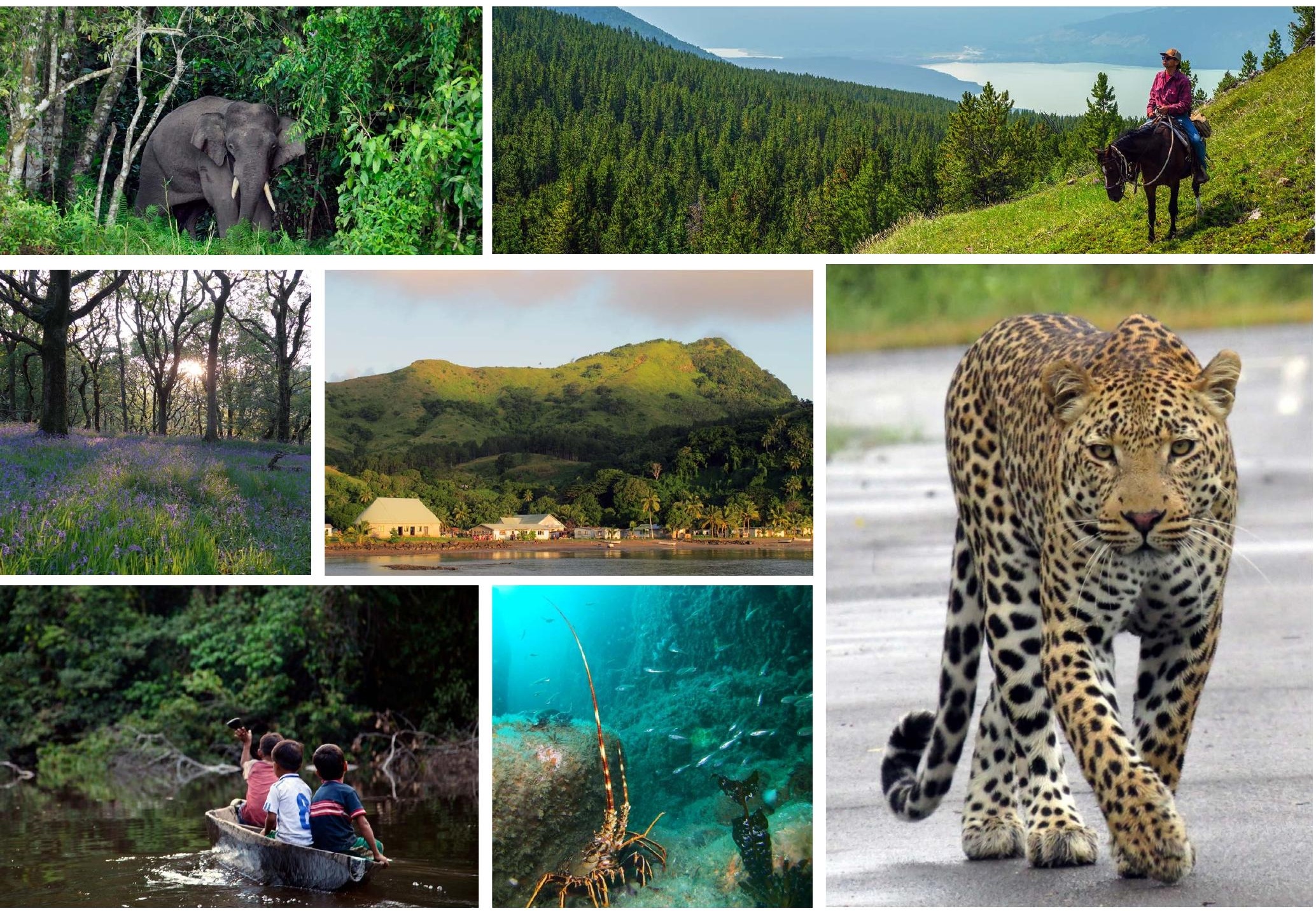

Série de Relatórios Técnicos sobre Áreas Protegidas $n^{\circ} 3$

Q29) WCPA 



\section{Reconhecer e relatar outras medidas efetivas de conservação baseadas em área}

Grupo de Trabalho da Comissão Mundial de Áreas Protegidas sobre OMECs 
A apresentação do material nesta publicação e as denominações empleadas para as entidades geográficas não implicadas em absoluto a expressão de uma opinião por parte da UICN ou de outra organização participante sobre a situação jurídica de um país, território da zona ou de sus autoridades , o acerca da demarcação de sus límites o fronteras.

As opiniões expressas nesta publicação não refletem necessariamente as opiniões da UICN ou das outras organizações participantes.

La UICN o demás organizaciones participantes não reivindican ninguna responsabilidad por los errores u omisiones que puedan ocurrir en la traducción a outros idiomas de este documento, cuya versión original es el idioma portugués. Em caso de discrepancia, remítase, por favor, a la edición original. Título de la edición original: Recognising and reporting other effective area-based conservation measures. no. 3 (2019). Publicado por: UICN, Gland, Suiça. DOI: https://doi.org/10.2305/IUCN.CH.2019.PATRS.3.en

\section{Publicado por: UICN, Gland, Suíça}

Direitos autorais: C 2019 UICN, União Internacional para a Conservação da Natureza e dos Recursos Naturais (C) 2021 UICN Escritório Regional da IUCN para a América do Sul para a tradução portuguesa

A reprodução desta publicação para fins educacionais ou outros fins não comerciais é autorizada sem permissão prévia por escrito do detentor dos direitos autorais, desde que a fonte seja totalmente referenciada.

É proibida a reprodução desta publicação para venda ou outros fins comerciais sem a permissão prévia por escrito do detentor dos direitos autorais.

Citação: Grupo de Trabalho da UICN-CMAP sobre OMECs (2021). Reconhecere relataroutras medidas efetivas de conservação baseadas em área. Gland, Suíça: UICN.

ISBN: 978-2-8317-2166-8 (PDF)

DOI: https://doi.org/10.2305/IUCN.CH.2019.PATRS.3.pt

Fotos da Capa: Superior à esquerda: Um elefante pigmeu caminha à beira do rio em uma zona governada pela comunidade, perto da aldeia de Abai, dentro do Sítio Ramsar das zonas úmidas do Baixo Kinabatangan-Segama, Sabah (Malásia). @ Harry Jonas. Superior à direita: William Myers de Yunesit'in, uma das seis comunidades Tsilhqot'in, em uma viagem a cavalo pelas montanhas do Parque Tribal Dasiqox (Colúmbia Britânica, Canadá). @ Jeremy Williams. Inferior à direita: Um leopardo caminha ao longo da pista da Base da Força Aérea de Hoedspruit, visto que a base mantém uma área de conservação a seu redor de aproximadamente 2.000 hectares, utilizada como zona de treinamento e de amortecimento civil (Hoedspruit, África do Sul). @ Base da Força Aérea Hoedspruit. Inferior ao centro: Um lugar histórico de naufrágios nas Ilhas de Scilly (Reino Unido) que exclui atividades e proporciona um meio ambiente sem perturbações para que a fauna marinha floresça. @ Dan Laffoley. Inferior à esquerda: Crianças locais explorando seus arredores em uma concessão para a conservação na Região de Loreto, Peru. ( B Bruno Monteferri. Centro à esquerda: A Reserva de Biosfera Dyfi, em Gales Central, está formada por uma mistura de áreas protegidas, geridas pelo governo e pela iniciativa privada, e terras privadas utilizadas principalmente para a criação de ovelhas e gado. Essas últimas incluem áreas, como bosques antigos, com alto valor em biodiversidade. Tais valores foram identificados por meio do processo de reconhecimento da reserva da biosfera e da sua implementação. Além disso, uma iniciativa multimilionária tem se dedicado a restaurar o processo natural no Vale Dyfi, que compreende montanhas, pastagens, bosques, turfeiras, um grande estuário e uma área marinha com extensos complexos de dunas de areia. Com uma área de pelo menos 10.000 hectares de terra e 28.400 hectares de mar, a área total provavelmente inclui uma gama de potenciais OMECs. (C) Equilibrium Research. Centro: Pôr do sol sobre o vilarejo Tovu, na llha Totoya (Fiji), onde os dirigentes comunitários participam das abordagens das áreas marinhas geridas localmente com um desenho em escala da paisagem marinha. @ Stacy Jupiter. Contracapa: Um jovem membro de uma família Bajau caminha através de um recife no início da noite (Sabah, Malásia). @ Harry Jonas.

Tradução: Kátia Silveira Salvado (Serviços de Tradução IBEC), Equador. Revisão técnica da tradução por Cláudio C. Maretti.

Notas da tradução:

- No Brasil, legalmente, as áreas protegidas stricto sensu criadas ou reconhecidas pelos governos são chamadas de "unidades de conservação". Mas essas definição e nomenclatura legais não necessariamente incluem toda a diversidade dos tipos de governança considerados pela UICN e sua CMAP. (Por exemplo, há uma categoria de unidade de conservação por privados, a Reserva Particular do Patrimônio Natural, quando oficialmente reconhecida, mas nem toda reserva privada é reconhecida como unidade de conservação.) O termo "áreas protegidas" no Brasil compreende outros tipos, inclusive aquelas não criadas com objetivos explícitos de conservação da natureza diferente da definição da UICN. (No entanto, com este sentido - de áreas criadas para a conservação da natureza -, o termo mais correto e usual internacionalmente é "áreas protegidas", como usado na maior parte do documento.)

- No Brasil têm sido usada a expressão "povos e comunidades tradicionais", para retratar povos indígenas e comunidades tradicionais e locais. Compreende-se, portanto, que há comunidades tradicionais, além dos povos indígenas. (O termo "comunidades locais" - usual na linguagem da CDB, junto com "povos indígenas" - não representa suficientemente o expressado em "comunidades tradicionais" no Brasil.)

- O termo "autoridade" usado em referência a áreas protegidas ou OMECs neste documento em geral não se refere a uma autoridade governamental, mas sim a quem tenha responsabilidade sobre a respectiva área (podendo ser também do campo privado ou comunitário, segundo os tipos de governança considerados pela UICN e sua CMAP).

- O termo "industrial" não se relaciona somente a implantações fabris, da indústria da transformação, mas sim atividades de nível industrial, de acordo com a Recomendação 102 de 2016 da UICN (WCC-2016-Rec-102-EN). (Essa perspectiva se diferencia daquela de uso sustentável por povos e comunidades tradicionais - ou povos indígenas e comunidades locais, segundo a linguagem usual da CDB.)

- O documento usa sistematicamente o verbo "relatar" pois se relaciona, menos com as decisões de como cada pais deve atuar, e mais com o que deve ser considerado válido para que cada país apresente (relate) à Convenção sobre Diversidade Biológica (CDB) e ao Banco de Dados Mundial de Áreas Protegidas (WDPA, na sigla em inglês) (Vale lembrar que há possibilidades de relato independente, não governamental, de TICCAs - ver https://www.iccaregistry.org/)

\section{Desenho e diagramação: Miller Design}

\section{Layout da versão em espanhol: Gabriel Hidalgo}

Disponível em: União Internacional para a Conservação da Natureza (UICN)

Programa Mundial de ÁreasProtegidas

wcpa@iucn.org

www.iucn.org/resources/publications 


\section{Índice}

Prefácio

Resumo executivo

Agradecimentos

vi

Glossário de termos

viii

Siglas e acrônimos

$\mathrm{X}$

Lista de quadros, tabelas e figuras

$\mathrm{X}$

1. Introdução 1

2. Definição e características 3

3. Identificar outras medidas efetivas de conservação baseadas em área na prática

4. Monitorar e relatar outras medidas efetivas de conservação baseadas em área

Referências

Anexo I A ampla relação entre as Metas de Aichi e a Meta 11

Anexo II Apoio à tomada de decisões: A Meta 11 de Aichi é a mais apropriada para avaliar uma medida de conservação?

Anexo III Banco de Dados Mundial de Áreas Protegidas 


\section{Prefácio}

Muitas áreas fora das redes de áreas protegidas nacionais e regionais também contribuem para a conservação efetiva in situ da biodiversidade. Reconhecer, relatar e apoiar de maneira adequada tais áreas é cada vez mais importante no contexto da perda de biodiversidade e da mudança climática. As Partes da Convenção sobre Diversidade Biológica (CDB) reconheceram já no Plano Estratégico da CDB (2011-2020) que as "outras medidas efetivas de conservação baseadas em área" (OMECs) oferecem uma significativa oportunidade para alcançar esse objetivo.

O assessoramento técnico do Grupo de Trabalho da Comissão Mundial de Áreas Protegidas (CMAP) da UICN sobre OMECs contribuiu para que $14^{\mathrm{a}}$ Conferência das Partes (COP, na sigla em inglês) da CDB adotasse uma definição, princípios orientadores, características e critérios comuns para a identificação das OMECs (Decisão 14/8 da CDB). O mundo tem agora a oportunidade de reconhecer melhor a conservação de facto que está acontecendo fora das áreas protegidas atualmente designadas e implementadas por um conjunto diverso de atores, incluindo os povos indígenas, as comunidades tradicionais e locais, o setor privado e as agências governamentais.

O reconhecimento apropriado das OMECs dá a oportunidade de envolver e apoiar os titulares de direitos e as partes interessadas e promover parcerias mais equitativas para os esforços mundiais de conservação, realçando a diversidade de contribuições para a conservação no âmbito global. De tal modo, as OMECs contribuirão para a conservação da biodiversidade em muitas maneiras, como: conservando os ecossistemas representativos importantes, habitats $e$ corredores de vida silvestre; apoiando a recuperação de espécies ameaçadas; mantendo as funções ecossistêmicas e garantindo seus serviços; aumentando a resiliência contra ameaças; e contribuindo para uma melhor gestão e restauração de áreas que poderiam ser úteis para a conservação in situ da biodiversidade em longo prazo. Além disso, as OMECs também podem contribuir com sistemas ecologicamente representativos e bem conectados de áreas protegidas e conservadas, integradas a paisagens terrestres e marinhas mais amplas.

Como qualquer "nova" abordagem, é provável que haja a necessidade constante de interpretação e implementação. Manter todo o valor das OMECs na promoção de uma conservação efetiva provavelmente exigirá esforços substanciais para construir capacidades nos níveis nacional e regional para identificar, monitorar e manter seus valores de biodiversidade. As OMECs são uma grande oportunidade para reconhecer e expandir o estado de conservação sob uma série de regimes de governança e gestão, segundo previsto na Meta 11 de Aichi. Um desafio chave será como reconhecer e apoiar essas áreas totalmente conservadas e, ao mesmo tempo, cumprir com as obrigações nacionais para uma gestão mais sustentável das atividades de produção, incluindo áreas de manejo florestal ou silvicultura, agricultura e pesca, de nível industrial, que, embora não cumpram com os critérios para que se classifiquem como uma OMEC, também contribuem para os Objetivos de Desenvolvimento Sustentável (ODS's).

Conforme as Partes da Convenção deliberarem sobre o Quadro de Biodiversidade Pós-2020, tais diretrizes continuarão realizando uma contribuição importante para garantir que as OMECs sejam reconhecidas adequadamente e contribuam tanto para as metas de cobertura da conservação como para as de representação ecológica por meio de "sistemas de áreas protegidas eOMECs".
Diretora-Geral Interina da União Internacional para a
Conservação da Natureza

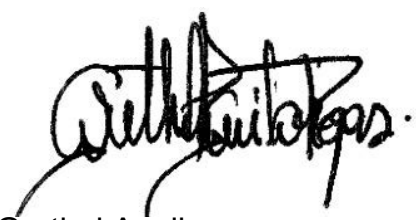

Dra. Grethel Aguilar

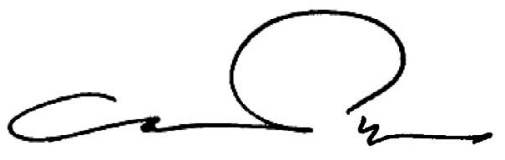

Dra. Cristiana Paşca Palmer

Secretária Executiva da Convenção sobre Diversidade Biológica 


\section{Resumo executivo}

OPlano Estratégico paraa Biodiversidade 2011-2020, adotado em Nagoya, proporciona um quadro para a implementação efetiva da CDB com 20 metas para o período de 2011-2020. A Meta 11 de Aichi declara que a conservação será alcançada por meio de sistemas de áreas protegidas, geridas de modo efetivo e equitativo, ecologicamente representativas e satisfatoriamente interligadas, e outras medidas efetivas de conservação baseadas em área. Embora já existissem definições e critérios claros para "áreas protegidas", não era o caso de "outras medidas efetivas de conservação baseadas em área". 1

Em novembro de 2018, tal situação foi resolvida quando, na COP 14 da CDB, as Partes adotaram uma definição de "outra medida efetiva de conservação baseada em área", bem como os princípios orientadores, as características comuns e os critérios para a identificação das OMECs (CDB/COP/ DEC/14/8). Na Decisão de 14/8, uma OMEC é definida como:

\section{Uma área geograficamente definida que não seja uma área protegida (stricto sensu), que seja governada e gerida de modo a alcançar resultados positivos e sustentáveis em longo prazo para a conservação in situ da biodiversidade, com funções e serviços ecossistêmicos associados e, quando aplicável, com valores culturais, espirituais, socioeconômicos e outros valores localmente relevantes.}

Embora as áreas protegidas devam ter como objetivo principal a conservação da natureza, para as OMECs isso não é necessário. As OMECs podem ser geridas visando vários objetivos diferentes, mas devem apresentar resultados efetivos de conservação. Nas OMECs, a conservação pode ser um objetivo principal ou secundário ou a conservação em longo prazo pode ser simplesmente um resultado complementar das atividades de gestão.

O reconhecimento das OMECs oferece uma grande oportunidade para que se reconheça a conservação de facto efetiva e em longo prazo que vem sendo realizada fora das áreas protegidas atualmente designadas, que se encontram sob uma série de regimes de governança e gestão, implementadas por um conjunto diverso de atores, incluindo os povos indígenas e as comunidades tradicionais e locais, o setor privado e as agências governamentais. As OMECs podem contribuir para que os sistemas de conservação sejam ecologicamente representativos e bem conectados, integrados a paisagens terrestres e marinhas mais amplas, gerando assim uma série de resultados positivos de conservação, tais como:

- A conservação de ecossistemas importantes, habitats e corredores de vida silvestre;

- O apoio à recuperação de espécies ameaçadas;

- A manutenção das funções e serviços ecossistêmicos;

- A melhora da resiliência perante ameaças; e

- A manutenção e a conectividade de remanescentes de ecossistemas fragmentados dentro de paisagens degradadas.

Este relatório foi elaborado pelo Grupo de Trabalho da CMAP sobre OMECs visando ajudar as Partes a interpretar e operacionalizar a Decisão 14/8, assim como começar a desenvolver um conjunto de boas práticas relacionadas com o reconhecimento e relato das OMECs. Ele está planejado para ser aplicado em várias escalas, que vão desde entender se uma área individual é uma OMEC, até apresentar estatísticas no âmbito nacional e mundial como meio para avaliar o progresso no alcance das metas de conservação.

A Seção 1 apresenta os antecedentes do conceito de "outras medidas efetivas de conservação baseadas em área" e um panorama geral do processo que resultou na Decisão 14/8 da CDB.

A Seção 2 estabelece a definição de OMEC e explica com clareza cada um de seus elementos ecritérios.

A Seção 3 estabelece um instrumento simples de triagem que pode ser utilizado para identificar áreas "candidatas a OMECs" e fornece uma lista com exemplos de potenciais OMECs, bem como áreas que provavelmente não cumpram com os critérios. É importante que a triagem e as avaliações posteriores sejam realizadas em cada uma das áreas para garantir que as mesmas cumpram com os critérios para alcançar uma conservação efetiva em longo prazo.

A Seção 4 apresenta os processos relevantes para monitorar e relatar as OMECs, com enfoque nas bases de dados mundiais do portal "Protected Planet", geridas pelo Centro para Monitoramento da Conservação Mundial (WCMC, na sigla em inglês) do Programa das Nações Unidas para o Meio Ambiente (PNUMA). 


\section{Agradecimentos}

\begin{abstract}
Estas diretrizes foram redigidas pelo Grupo de Trabalho da UICN-CMAP sobre Outra medida efetiva de conservação baseada em área, estabelecido em 2015, o qual trabalhou durante três anos para apoiar um processo no quadro da CDB que resultou na Decisão 14/8 da CDB sobre "áreas protegidas e outras medidas efetivas de conservação baseadas em área", adotada por 196 membros da COP 14 (novembro de 2018). Esse assessoramento técnico relaciona-se diretamente com a Decisão 14/8 da CDB sobre o reconhecimento e relato de outras medidas efetivas de conservação baseadas em área (OMECs), que são por vezes denominadas áreas conservadas.
\end{abstract}

O Grupo de Trabalho foi copresidido por Kathy MacKinnon (Presidente da CMAP, Reino Unido) e Harry Jonas (Reino Unido/Malásia) e está composto por mais de 120 membros especialistas. O rascunho foi editado pelos Copresidentes e um grupo editorial integrado por Nigel Dudley (ReinoUnido), Marc Hockings (Austrália), Dan Laffoley (Reino Unido), David MacKinnon (Canadá), Trevor Sandwith (África do Sul) e Stephen Woodley(Canadá).

\section{Realizaram-se quatro oficinas com especialistas do} Grupo de Trabalho: em Cambridge, Inglaterra (janeiro de 2016), Vilm, Alemanha (julho de 2016 e julho de 2019) e Vancouver, Canadá (fevereiro de 2017). A CMAP-UICN deseja agradecer à Agência Federal Alemã para a Conservação da Natureza (BfN), ao Departamento Federal Suíço do Meio Ambiente, ao SwedBio e à Sociedade Canadense de Parques e Vida Silvestre (CPAWS) por suas contribuições financeiras para o Grupo de Trabalho. Somos gratos também aos funcionários do WCMC do PNUMA em Cambridge (Reino Unido), a Gisela Stolpe e Bettina Ohnesorge (BfN) em Vilm (Alemanha) e a Sabine Jessen (CPAWS), em Vancouver (Canadá), por seu apoio logístico na organização e realização dessas reuniões. Também agradecemos a Sarat Gidda e aos colegas da Secretaria da CDB por seu engajamento ativo durante todo o processo, incluindo a organização conjunta de diversos eventos paralelos durante as reuniões das Partes.

\section{Durante o processo de desenvolvimento, membros} do Grupo de Trabalho e outros especialistas proporcionaram feedback, informação e estudos de casos muito valiosos. Agradecemos às seguintes pessoas por suas contribuições (aqueles que colaboraram com estudos de casos estão marcados com um asterisco): Agnes Agama (Malásia), TundiAgardy (EUA), Khaled Allam Harhash (Egito), HelenaAlvez-Pinto(Brasil), Thora Amend* (Alemanha), Michele Andrianarisata* (Madagascar), Ny Aina Andrianarivelo* (Madagascar), Ludi Apin (Malásia), Alexandra Areiza (Colômbia), Clarissa Arida (Filipinas), Peter Auster(EUA), Ghanimat Azhdari (Irã), Tim Badman (Reino Unido/Suíça), Megan Barnes (Austrália), Juan BezauryCreel (México), Seema Bhatt (Índia), Dominique Bikaba (República Democrática do Congo), Heather Bingham* (Reino Unido), Grazia Borrini Feyerabend* (Itália/Suíça),
Peter Bridgewater (Austrália), Johnny Briggs (Reino Unido), Thomas Brooks (Reino Unido/Suíça), Jessica Brown* (EUA), Jens Bruggemann* (Alemanha), Neil Burgess (Reino Unido), Catie Burlando (Itália), Stuart Butchart (Reino Unido), Pete Chaniotis (Reino Unido), Maria Elfi Chávez (Colômbia), Gladman Chibememe (Zimbábue), Christie Chute* (Canadá), Pepe Clark (Austrália/Reino Unido), Peter Cochrane (Austrália), Laura Cornick (Reino Unido), Mark Costello (Nova Zelândia), Mason Croft (EUA), Adrian Davey (Austrália), Mimi D'lorio (EUA), Pablo Dominguez (Espanha), Paul Donald* (Reino Unido), Alkaly Doumbouya* (Guiné), Lisa Duarte (EUA), Steve Edwards (Reino Unido/Suiça), Hany El Shaer (Egito), Cristina Eghenter* (Itália), Shahul Faizi Hameed (Índia), Edgar Fernández(CostaRica), GregorFischenich(Alemanha), Vin Fleming (Reino Unido), Amelia Fowles (Austrália), Christine Franklin (EUA), Sandra Galán (Colômbia), Delfin Ganapin (Filipinas), Carolina Garcia Imhof (Colômbia), Sonali Ghosh (Índia), Rachel Golden Kroner (EUA), Hugh Govan (Reino Unido/Fiji), Stephen Grady (Reino Unido), Tarsicio Granizo (Equador), Ania Grobicki (África do Sul/Suíça), Catalina Gutierrez (Colômbia), James Hardcastle (Reino Unido/ Suiça), TerenceHay-Edie(Suíça/Tailândia), Yifan(Flora)He (China), Robert Hélie (Canadá), Ro Hill (Austrália), Amber Himes-Cornell (EUA), Marc Hockings (Austrália), Elaine Hsiao (Canadá), Claudia Ituarte Lima (México), Sabine Jessen* (Canadá), Holly Jonas (Canadá/Malásia), Stacy Jupiter (EUA/Ilhas Fiji), Theodore Karfakis (Grécia), Jennifer Kelleher (Irlanda), Kate Kincaid (Canadá), Jonathan Kirui (Quênia), Rebecca Klaus (Reino Unido), Naomi Kingston* (Irlanda/ Reino Unido), Eskild Kirkegaard (Dinamarca), Mirjam de Konig (Países Baixos), Sigrid Kuehnemund (Canadá), Barbara Lang (Alemanha/Benin), Thierry Lefebvre (França), Christopher Lemieux (Canadá), Clare Lewis (Reino Unido), Harvey Locke (Canadá), Julia Miranda Londono (Colômbia), Ali Mahamane (Nigéria), Cláudio C. Maretti (Brasil), Michael Mascia (EUA), Lisa McLaughlin (Canadá), Daniel Marnewick (África do Sul), Clara Lucía Matallana-Tobón* (Colômbia), Pradeep Mehta (Índia), Mehmet Metaj (Albânia), Rossana Merizalde (EUA), Amy Milam (EUA), Carmen Miranda (Bolívia), Brent Mitchell* (EUA), Rahul Mungikar (Índia) Daniel Mwamidi (Quênia), Helen Newing (Reino Unido), Onkemetse Nteta* (África do Sul), Melissa Jane Nursey-Bray (Austrália), Aboubacar Oularé (Guiné), Gisela Paredes (Colômbia), Roberto Pereyra Lobos (Argentina), Jacques Perron* (Canadá), DimitraPetza(Grécia/ Itália), Hugh Possingham (Austrália), JeffPradel(Peru), Madhu Rao (Índia/Reino Unido/Singapura), Andrew Rhodes* (México), Ryan Richards (EUA), Danielle Ryan (Austrália), Marina Rosales (Peru), Carlos Saavedra (Colômbia), Yoav Sagi (Israel), Marcela Santamaria (Colômbia), Elsa Sattout (Líbano), Klaus Schmitt* (Alemanha), Faizi Shahul Hameed (Índia), SushmaShresthma (Nepal/EUA) Joanna Smith (Canadá), Dermot Smyth (Austrália), Clara Solano (Colômbia), Mark Spalding (Reino Unido), Candice Stevens (África do Sul), Todd Stevenson (EUA), Mavra Stithou (Grécia), Sue Stolton (Reino Unido), Teki Surayya (Índia), Kim Taylor Thompson* (Canadá), Parfait Tchuenfo (Camarões), Anteneh Tesfaw (Etiópia), David Thomas 
(Reino Unido), Ted Trzyna (EUA), Agus Utomo* (Indonésia), Bas Verschuuren (Holanda), Francis Vorhies (Reino Unido), John Waithaka* (Quênia), Sonam Wangchuk* (Butão), James Watson (Austrália), Sue Wells (Reino Unido), Sheila WertzKanounnikoff (Alemanha), Tara Whitty (EUA), Hesti Widodo* (Indonésia), Ryan Wilkie (Reino Unido/Dinamarca), James Williams (Reino Unido), Linda Wong (China), Dale Wright (África do Sul), Kim SanderWright* (Canadá), Llewellyn Young* (Hong Kong/Suíça), Hag Young Heo (República da Coreia)e Jinfeng Zhou (China).

\section{Outras pessoas que gentilmente contribuíram com} dados ou estudos de casos: Simon Albert (Austrália), Eugenio Barrios (México), Alexandra Barron (Canadá), Nicole Bendsen (Alemanha), Bastian Bertzky (África do Sul/Itália), Caroline Butler (Canadá), Tony Charles (Canadá), Sushila ChatterjeeNepali (Nepal), Roger Crofts (Reino Unido), Terence Dacles (Filipinas), Steve Diggon (Canadá), William Dunbar (EUA/Japão), Kim Dunn (Canadá), Jessica Elliott (Canadá), Ninel Escobar (México), Roman Eyholzer (Suíça), Fred Ford (Austrália), Robyn Forrest (Canadá), Kim Friedman (Austrália/ Itália), Mervi Heinonen (Finlândia), Erich Hoyt (EUA/Reino Unido), Olaf Jensen (Canadá), François Lengrand (França), Satnam Manhas (Canadá), Joe McCarter (Nova Zelândia), Martine Maron (Canadá), Chris McDougall (Canadá), Günter Mühlbauer(Alemanha), Mariana Zareth Nava Lopez (México), Saw Tun Khaing (Mianmar), Linda Nowlan (Canadá), Shane Orchard (Nova Zelândia), Allison Pritchard (Canadá), Ravaka Ranaivoson (Madagascar), Sergio Salinas-Rodríguez (México), Paul Scholte (Alemanha), Archana Sharma (EUA), Rebecca Singleton (Reino Unido/Canadá), Charlotta Sörqvist (Suécia), Bruce Stewart (Canadá), Gary Tabor (EUA), Kaori Tsujita (Japão), Siyu Qin (China/EUA), Basile Van Havre (Canadá), Liette Vasseur (Canadá), Scott Wallace (Canadá), Bill Wareham (Canadá), Gladys Warigia Njoroge (Quênia), Mike Wong (Canadá), Alison Woodley (Canadá), Edgar Yerena (Venezuela) e Natori Yoji (Japão).

A CMAP da UICN também agradece a John Waithaka e a Lucy Waruingi, que organizaram uma oficina no Quênia sobre a proposta de diretrizes em 2017, e às seguintes pessoas que testaram as orientações localmente em Bermudas: Alison Copeland, Peter Drew, Dan Laffoley, Jeremy Madeiros, Sarah Manuel, Simieon Massey, Drew Pettit, JoannaPitt,
Philippe Rouja, Mandy Shailer, Robbie Smith, Tammy Trott, Craig Trott e Julie Marshall. A produção de um grande número de estudos de casos na Colômbia foi liderada por Clara Matallana (Instituto Humboldt), com o apoio de Alexandra Areiza, Maria Elfi Cháves, Sandra Galán, Clara Solano e Marcela Santamaria, e contribuições de Jony Albeiro Arias, Luis Alimaco, Germán Andrade, Mónica Arroyave, Atanasio Barros, Hermes Carreño, Claudia Céspedes, Stephanie Gailer, Daniel Garavito, Pedro Garavito, Carolina Gil, Brian Hettler, Eduardo Londoño, Juanita Londoño, Jorge Hernán López, Ricardo Rey, Jerónimo Rodríguez Escobar, Alejo Sauna Mamatacán, Dignory Soto Londoño, José de los Santos Sauna, José Shibulata Zarabata, Carlos Vieira e Jacinto Zarabata.

O processo beneficiou-se do trabalho realizado pelo Conselho Canadense de Áreas Ecológicas para desenvolver um guia sobre outras medidas efetivas de conservação baseadas em área (MacKinnon et al., 2015) e está complementado com o trabalho sobre a relação entre Áreas Chave de Biodiversidade (KBAs, na sigla em inglês), áreas protegidas e outras medidas efetivas de conservação baseadas em área lideradas pela BirdLife International e seus parceiros (BirdLife, 2017). Realizaram-se oficinas para testar as versões preliminares do guia no Quênia, Colômbia, Bermudas e África do Sul. Uma edição especial da revista PARKS (CMAP-UICN, 2018) apresenta alguns exemplos de estudos de casos, consultar: https://parksjournal.com/list-of-papers/.

Para mais informação sobre o Grupo de Trabalho, incluindo todos os produtos e estudos de casos, consultar: www.iucn. org/theme/protected-áreas/wcpa/what-we-do/oecms.

Por favor, enviar qualquer pergunta ou comentário para: oecm@wcpa.iucn.org 


\section{Glossário de termos}

\begin{abstract}
Abordagem ecossistêmica: Estratégia para a gestão integrada da terra, da água e dos recursos vivos, que promove a conservação e o uso sustentável de maneira equitativa. Sua aplicação ajuda a alcançar um equilíbrio entre os três objetivos da CDB. Baseia-se na aplicação de metodologias científicas apropriadas centradas nos níveis de organização biológica que compreendem os processos, as funções e as interações essenciais entre os organismos e seu ambiente. Reconhece que os humanos, com sua diversidade cultural, são um componente integral dos ecossistemas. (https://www.cbd.int/ecosystem/).
\end{abstract}

Área marinha gerida localmente: Área de águas próximas ao litoral e seus recursos costeiros e marinhos associados, gerida em grande medida ou totalmente em nível local pelas comunidades costeiras, pelos grupos proprietários de terras, pelas organizações parceiras ou representantes e colaboradores governamentais que moram ou têm sua sede em uma área imediata. (LMMA, na sigla usual em inglês.) (http://lmmanetwork. org/)

Área protegida: A CDB define uma área protegida como: "Uma área geograficamente definida que é designada ou regulada e gerida para alcançar objetivos específicos de conservação" (Artigo 2 da CDB). A UICN tem uma definição mais detalhada: "Um espaço geográfico claramente definido, reconhecido, dedicado e gerido através de meios legais ou outros meios efetivos para alcançar a conservação em longo prazo da natureza, com os serviços ecossistêmicos e os valores culturais associados" (Dudley, 2008). A CDB e a UICN reconhecem essas duas definições como equivalentes na prática (Lopoukhine \& Dias, 2012), visto que em ambos casos tais áreas estão destinadas a alcançar a conservação in situ.

Áreas conservadas: As Partes da CDB e outras organizações referem-se cada vez mais a "áreas protegidas e conservadas" (ver, por exemplo, a Decisão 14/8 da CDB e a Lista Verde de Áreas Protegidas e Conservadas da UICN). Nesse contexto, "áreas conservadas" inclui áreas que podem cumprir com os critérios para OMECs.

\section{Áreas Marinhas Ecológica ou Biologicamente}

Significantes: Áreas importantes do oceano que servem para propósitos importantes, de um modo ou outro, para viabilizar o funcionamento saudável dos oceanos e os vários serviços que estes proporcionam. (EBSAs, na sigla no inglês usual da CDB.) (https://www.cbd.int/ebsa/).

Autoridade de gestão: Organização ou entidade responsável pela gestão contínua de um lugar. Pode ou não ser a mesma que exerce a autoridade de governança, a organização ou entidade que tem a autoridade legal ou costumeira e a responsabilidade pelo lugar.

Autoridade de governança: Instituição, pessoa, povos indígenas, grupo comunitário ou outro corpo no qual se reconheça autoridade e responsabilidade na tomada de decisões e gestão de uma área.
Biodiversidade: Variabilidade de organismos vivos de todas as fontes, incluindo, entre outros elementos, os ecossistemas terrestres e marinhos e outros ecossistemas aquáticos e os complexos ecológicos dos quais formam parte. Isso inclui a diversidade dentro de cada espécie, entre as espécies e dentre os ecossistemas. (Artigo 2 da CDB.)

Candidato a OMEC: Espaço geograficamente definido, identificado como uma "OMEC potencial" pela autoridade que exerce a governança e que possui seu consentimento para ser avaliado de acordo com os critérios da CDB.

\section{Consentimento livre, prévio e informado: Direito} específico que concerne aos povos indígenas e tradicionais. É reconhecido na Declaração das Nações Unidas sobre os Direitos dos Povos Indígenas. Permite-lhes dar ou negar seu consentimento a um projeto que possa afetá-los ou a seus territórios. Uma vez que eles deem seu consentimento, podem retirá-lo em qualquer momento. Além disso, esse direito permite que eles negociem as condições sob as quais o projeto será desenhado, implementado, monitorado e avaliado. Isso está incorporado ao direito universal à autodeterminação. (ONU, 2007.)

\section{Conservação in situ: Conservação de ecossistemas e} habitats naturais e manutenção e recuperação de populações viáveis de espécies em seus ambientes naturais e, no caso de espécies domesticadas ou cultivadas, nos ambientes onde desenvolveram suas propriedades distintivas. (Artigo 2 da CDB.)

Ecossistema: Complexo dinâmico de comunidades de plantas, de animais e de micro-organismos e seu ambiente não vivo que interagem como uma unidade funcional. (Artigo 2 da CDB.)

Geodiversidade: Classificação natural (diversidade) de características geológicas (rochas, fósseis, minerais), geomorfológicas (forma do terreno, processos físicos) e do solo e inclui suas formações, relações, propriedades e sistemas. (Gray, 2004.)

Habitat: Lugar ou tipo de ambiente onde um organismo ou população existe naturalmente. (Artigo 2 da CDB.)

OMEC potencial: Espaço geograficamente definido e identificado com as características pertinentes para ser uma OMEC por meio da aplicação do instrumento de triagem, mas onde a autoridade de governança ainda não concedeu seu consentimento para que se torne um "candidato a OMEC".

\section{Povos indígenas e comunidades tradicionais e locais:} Este relatório segue os usos dos termos "povos indígenas" e "comunidades locais" da CDB.

Uso sustentável: Uso de componentes de diversidade biológica de um modo e com um ritmo que não cause o 
declínio em longo prazo da diversidade biológica, mantendo seu potencial para satisfazer as necessidades e aspirações das gerações presentes e futuras. (Artigo 2 da CDB).

Valores culturais e espirituais: Valores recreativos, religiosos, estéticos, históricos e sociais relacionados aos benefícios tangíveis e intangíveis que a natureza e as caraterísticas naturais proporcionam às pessoas de diferentes culturas e sociedades, com um enfoque particular nos que contribuem para os resultados de conservação (por exemplo, as práticas tradicionais de gestão das quais as espécies chave, a biodiversidade ou os ecossistemas completos tornaram-se dependentes, ou o apoio social para a conservação de paisagens para a manutenção de sua qualidade em relação a sua expressão artística ou beleza) e de patrimônio intangível, incluindo práticas culturais e espirituais. 


\section{Siglas e acrônimos}

$\begin{array}{ll}\text { AIMM } & \text { Área Importante para os Mamíferos Marinhos (IMMAs, na sigla em inglês) } \\ \text { CDB } & \text { Convenção sobre Diversidade Biológica } \\ \text { CMAP } & \text { Comissão Mundial de Áreas Protegidas da UICN } \\ \text { COP } & \text { Conferência das Partes da CDB (sigla em inglês) } \\ \text { EBSA } & \text { Área Marinha Ecológica ou Biologicamente Significante (sigla em inglês) } \\ \text { GD-PAME } & \text { Banco de Dados Mundial de Efetividade de Gestão de Áreas Protegidas } \\ \text { IBA } & \text { Área Importante para a Conservação das Aves (sigla em inglês) } \\ \text { IPA } & \text { Área Importante para as Plantas (sigla em inglês) } \\ \text { KBA } & \text { Área Chave de Biodiversidade (sigla em inglês) } \\ \text { LMMA } & \text { Área marinha gerida localmente (sigla em inglês) } \\ \text { ODS's } & \text { Objetivos deDesenvolvimento Sustentável da ONU } \\ \text { OMEC } & \text { Outra medida efetiva de conservação baseada em área } \\ \text { ONU } & \text { Organização das Nações Unidas } \\ \text { PAME } & \text { Efetividade de gestão de áreas protegidas (sigla em inglês) } \\ \text { PNUMA } & \text { Programa das Nações Unidas para o Meio Ambiente (também chamado de ONU Ambiente) } \\ \text { SBSTTA } & \text { Órgão Subsidiário de Assessoramento Científico, Técnico e Tecnológico da CDB (sigla em inglês) } \\ \text { TICCAs } & \text { Territórios eáreas conservados por povos indígenas e comunidades tradicionais e locais } \\ \text { UICN } & \text { (ICCAs,na sigla em inglês) } \\ \text { WCC } & \text { União Internacional para a Conservação da Natureza } \\ \text { WCMC-PNUMA } & \text { Congresso Mundial de Conservação (sigla em inglês) da UICN } \\ \text { WDPA } & \text { Centro para Monitoramento da Conservação Mundial (sigla em inglês) da ONU Meio Ambiente } \\ & \text { Banco de Dados Mundial de Áreas Protegidas (sigla em inglês) } \\ & \end{array}$

\section{Lista de quadros, tabelas e figuras}

Quadro 1: $\quad$ Identificar ou estabelecer outras medidas efetivas de conservação baseadas em área 3 Quadro 2: $\quad$ Um olhar mais próximo ao espaço geográfico $\quad 5$

Quadro 3:. $\quad$ Sítios de naufrágios históricos, como o Scapa Flow - um exemplo de conservação secundária 6

Quadro 4: $\quad$ Um olhar mais atento à biodiversidade 7

Quadro 5: $\quad$ Usar o instrumento de triagem - pontos chave a tratar 8

Quadro 6: $\quad$ Assegure-se que a Meta 11 de Aichi seja o enfoque correto 10

Quadro 7: $\quad$ Restauração ecológica nas outras medidas efetivas de conservação baseadas em área 12

Tabela 1: $\quad$ Princípios básicos para a verificação de informação para incluir na base de dados do "Protected Planet" 13

Figura 1: $\quad$ A relação entre OMECs e áreas protegidas 4 


\section{Introdução}

\section{Antecedentes}

O Plano Estratégico para a Biodiversidade 2011-2020 é um quadro para a implementação efetiva da CDB por meio de uma abordagem estratégica, que compreende uma visão compartilhada, uma missão e objetivos e metas estratégicos ("Metas de Aichi para a Biodiversidade") que inspiraram uma ação ampla de todas as Partes (os países signatários dessa convenção) e atores interessados. Em relação ao Objetivo Estratégico C, a Meta 11 tem como objetivo melhorar o estado da biodiversidade salvaguardando os ecossistemas, as espécies e a diversidade genética. Ela estabelece que:

Até 2020, pelo menos 17\% das áreas terrestres e de águas continentais e $10 \%$ das áreas marinhas e costeiras, especialmente as áreas de especial importância para a biodiversidade e para os serviços ecossistêmicos, terão sido conservadas por meio de sistemas de áreas protegidas e outras medidas efetivas de conservação baseadas em área, geridos de modo eficiente e equitativo, ecologicamente representativose satisfatoriamente conectados, e integradas às paisagens terrestres e marinhas mais amplas. ${ }^{2}$

As áreas protegidas constituem a base das estratégias nacionais para a conservação da biodiversidade e para o cumprimento da Meta 11 (Watson et al., 2014). A UICN proporcionou orientação sobre a definição, as categorias de gestão e os tipos de governança de áreas protegidas (Dudley 2008; Borrini-Feyerabend et al., 2017). As Partes da CDB incluíram as OMECS na Meta 11, visto que algumas áreas fora das redes reconhecidas de áreas protegidas também contribuem para uma conservação efetiva in situ da biodiversidade. Estas podem incluir territórios e áreas conservadas geridas por qualquer um dos quatro tipos de governanças: governos, atores privados, povos indígenas e comunidades tradicionais e locais e arranjos de governança compartilhados. Independentemente das conquistas alcançadas com a Meta 11 até 2020, espera-se que as áreas protegidas e as OMECs sejam parte de qualquer meta pós2020 para conservar a biodiversidade in situ e que as OMECs se convertam em um instrumento de uso mais comum nas estratégias de conservação.

Desde 2010, as Partes da CDB progrediram significativamente na expansão dos sistemas de áreas protegidas, incluindo a declaração de muitas áreas marinhas protegidas de grandes dimensões (WCMC-PNUMA e UICN 2016, 2018). Contudo, em relação à definição, à identificação, ao reconhecimento e ao relato das OMECs (Jonas et al., 2014), o progresso foi menor. A UICN e a sua CMAP foram convidadas pelas Partes da CDB para "elaborar orientações técnicas para alcançar o escopo completo da Meta 11 de Aichi para a Biodiversidade" (Decisão XI/24 da CDB). Em 2015, a CMAP estabeleceu um grupo de trabalho para elaborar orientações técnicas sobre OMECs.
Uma proposta de diretrizes foi preparada, entregue para o Secretariado da CDB, compartilhada com as Partes, discutida em duas oficinas convocadas pela CDB (fevereiro de 2018) e apresentada em eventos paralelos do Órgão Subsidiário de Assessoramento Científico, Técnico e Tecnológico (SBSTTA) da CDB (2016-2018). Mais informação sobre o processo de elaboração das diretrizes está disponível em uma edição especial da revista PARKS sobre OMECs (Jonas et al., 2018).

Na COP 14, realizada em novembro de 2018, as Partes adotaram uma decisão sobre "Áreas protegidas e outras medidas efetivas de conservação baseadas em área" (CDB/COP/ DEC/14/8, https://www.cbd.int/doc/decisions/cop-14/cop-14-dec-08-en.pdf), que adotou uma definição para OMEC e critérios para sua identificação e gestão.

A Decisão 14/8, no parágrafo 9, convidou a UICN e outros corpos de especialistas para que continuassem ajudando as Partes na identificação das OMECs e oferecendo assessoramento científico e técnico sobre os critérios para sua identificação.

\section{Elaboração das diretrizes}

Estas diretrizes foram preparadas pelo Grupo de Trabalho da CMAP sobre OMECs em resposta à solicitação da COP 14 para ajudar as Partes a operacionalizar a Decisão 14/8. Estão desenhadas para serem aplicadas em várias escalas, desde entender se uma área individual é uma OMEC até relatar estatísticas em nível nacional e global, como um meio para avaliar o progresso no alcance das metas de conservação. Para a elaboração dessas diretrizes, aproveitou-se o trabalho realizado pelo Conselho Canadense de Áreas Ecológicas para o desenvolvimento de orientações sobre OMECs (MacKinnon et al., 2015) e complementou-se com o trabalho sobre a relação entre KBAs (UICN, 2016), áreas protegidas e OMECs dirigido pela BirdLife International e parceiros (Donald et al., 2019).

Os públicos principais para essas diretrizes são as Partes da CDB, agências governamentais, organismos da ONU, organizações não governamentais, organizações privadas, organizações dos povos indígenas e comunidades tradicionais e locais e outras organizações interessadas, organismos e pessoas envolvidas no entendimento, na aplicação e no acompanhamento dos avanços realizados para o alcance da Meta 11 de Aichi e outras metas de conservação. As OMECs também contribuirão direta e indiretamente para o alcance de vários ODS's da ONU. A implementação também informará o processo da CDB para desenvolver o Quadro de Biodiversidade Pós-2020 e o alcance dos ODS's, particularmente no contexto de novos enfoques de

Texto original em inglês da CDB (acrescentado pela tradução): Aichi Target 11: "By 2020, at least 17 per cent of terrestrial and inland water, and 10 per cent of coastal and marine areas, especially areas of particular importance for biodiversity and eco system services, are conserved through effectively and equitably managed, ecologically representative and well connected systems of protected areas and other effective area-based conservation measures, and integrated into the wider landscapes and seascapes." 
conservação de paisagens terrestres e marinhas (CDB, 2019). Essas diretrizes se aplicam a todos os ambientes terrestres, de água doce e marinhos. Para tal, essas devem servir como base para outros processos, incluindo as discussões sobre tratados internacionais juridicamente vinculantes para implementar áreas marinhas protegidas em alto mar.

\section{Conteúdo das diretrizes}

Estas diretrizes fornecem informação sobre como aplicar a definição das OMECs na conservação nos níveis internacional, nacional, subnacional ou local e relatá-las ao Banco de Dados Mundial de Áreas Protegidas (WDPA) e à CDB. Explicam a definição de OMEC e instrumentos e enfoques recomendados para identificação, reconhecimento, monitoramento e relato. Outras seções tratam a relação com outras Metas de Aichi para a Biodiversidade, as diferenças entre áreas protegidas e OMECs e como se fazem os registros no WDPA. De acordo com a Decisão 14/8, essas diretrizes mostram como as OMECs se aplicam dentro de um quadro de princípios existentes estabelecidos pela CDB, pela UICN e por parceiros, em relação à conservação da biodiversidade, aos direitos humanos e ao desenvolvimento sustentável.

Ao alcançar uma conservação efetiva in situ da biodiversidade, as OMECs podem contribuir para manter os valores da biodiversidade existentes e melhorar os resultados de conservação da biodiversidade, como, por exemplo, através da conservação de ecossistemas, habitats e corredores de vida silvestre importantes, do apoio para a recuperação de espécies ameaçadas, da manutenção das funções ecossistêmicas e de seus serviços, do aumento da resiliência perante ameaças e da preservação e da conectividade de remanescentes de ecossistemas fragmentados em paisagens degradadas. As OMECs também podem contribuir para a formação de redes de conservação ecologicamente representativas e satisfatoriamente interligadas, integradas a paisagens terrestres e marinhas mais amplas.

A identificação das OMECs e o reconhecimento de suas estruturas de governança e gestão oferecem uma oportunidade de envolver e apoiar um conjunto de novos parceiros nos esforços de conservação global. Em alguns contextos, isso permite o diálogo e promove a reconciliação mediante o reconhecimento apropriado das "áreas indígenas conservadas e protegidas" (Indigenous Circle of Experts, 2018). O reconhecimento como OMEC também pode proporcionar incentivos adicionais para a conservação e para a gestão sustentável de áreas importantes para a biodiversidade fora das áreas protegidas, como as Áreas Chave de Biodiversidade (KBAs), Áreas Importantes para as Plantas (IPAs), Áreas Importantes para a Conservação das Aves (IBAs), Áreas Importantes para os Mamíferos Marinhos (IMMAs) e Áreas Marinhas Ecológica e Biologicamente Significantes (EBSAs), observando que tais áreas devem cumprir com a definição de OMEC para serem incluídas. A aplicação dessas diretrizes também pode contribuir para melhorar a governança ou a gestão das áreas candidatas a OMECs. 


\section{Definição e características}

Esta parte estabelece a definição de OMEC e fornece orientação sobre cada um de seuselementos.

\subsection{Definição de "outra medida efetiva de conservação baseada em área" ${ }^{3}$}

\author{
A CDB, na Decisão 14/8, define uma OMEC como:
}

Uma área geograficamente definida que não seja uma área protegida, que seja governada e gerida de modo a alcançar resultados positivos e sustentáveis em longo prazo para a conservação in situ da biodiversidade, com funções e serviços ecossistêmicos associados e, quando aplicável, com valores culturais, espirituais, socioeconômicos e outros valores localmente relevantes. (A partir de CDB, 2018. $)^{4}$

A definição de OMEC complementa a definição da UICN de área protegida (Dudley, 2008). A UICN define uma área protegida como:

\section{Um espaço geográfico claramente definido, reconhecido, dedicado e gerido através de meios legais ou outros tipos de meios efetivos para alcançar a conservação em longo prazo da natureza e de seus serviços ecossistêmicos e valores culturais. ${ }^{5}$}

O critério distintivo é que uma área protegida tem um objetivo principal de conservação, enquanto uma OMEC apresenta resultados de conservação efetiva in situ da biodiversidade, independentemente de seus objetivos.

Quadro 1:

\section{Identificação ou estabelecimento de outras medidas efetivas de conservação baseadas em área}

Supõe-se que tanto áreas protegidas como OMECs apresentam resultados de conservação in situ da biodiversidade efetiva em longo prazo. Contudo, embora as áreas protegidas tenham a conservação da natureza como seu objetivo principal de gestão, as OMECs podem ou não ter a conservação da natureza como um objetivo.

Tipos de enfoques que permitem uma conservação efetiva nas OMECS

1. "Conservação principal"- Refere-se às áreas que cumprem com todos os elementos da definição da UICN sobre uma área protegida, mas não são designadas oficialmente como tal porque a autoridade de governança não quer que a área seja reconhecida ou relatada como área protegida. Por exemplo, em alguns casos, os povos indígenas e as comunidades tradicionais e locais não querem que as áreas de alto valor de biodiversidade que governam sejam designadas como áreas protegidas nem registradas nas bases de dados de áreas protegidas do governo. Assumindo que uma área cumpra com os critérios de uma OMEC, a autoridade tem o direito de dar ou não seu consentimento para que a área seja reconhecida como OMEC.

2. "Conservação secundária" - A conservação é alcançada mediante a gestão ativa de uma área onde os resultados de biodiversidade são um objetivo secundário de gestão. Por exemplo, políticas duradouras de proteção e gestão das bacias hidrográficas podem resultar em uma proteção efetiva da biodiversidade nessas bacias, embora as áreas possam ser geridas principalmente com objetivos distintos aos da conservação da biodiversidade. Sítios geridos para proporcionar conectividade ecológica entre áreasprotegidas ou outras áreas de alta biodiversidade, contribuindo assim para sua viabilidade, também podem ser qualificados como OMECs.

3. "Conservação complementar" - Refere-se a áreas que oferecem conservação in situ como um subproduto das atividades de gestão, embora a conservação da biodiversidade não seja um objetivo de gestão. Por exemplo, Scapa Flow, nas llhas Órcades, protege naufrágios e tumbas de guerra, permitindo a conservação complementar de uma importante biodiversidade (ver Quadro3).

Áreas não reconhecidas nem relatadas que cumprem com a definição de área protegida

A UICN recomenda que as áreas que cumpram com todos os elementos de sua definição de área protegida e que são reconhecidas como tal pela autoridade de governança sejam consideradas como áreas protegidas em vez de OMECs (ver Figura 1 e Parte 4). Por exemplo, algumas áreas protegidas privadas não são relatadas como áreas protegidas pelos governos nacionais, embora cumpram com os critérios da UICN.

\section{Outras áreas naturais intactas}

Todos os casos anteriores devem ser diferenciados de outras áreas naturais intactas que não estão sujeitas a nenhuma forma deliberada de gestão de conservação, mas que, apesar disso, possuem atualmente uma biodiversidade intacta, devido a, por exemplo, localização remota ou situações de conflito. Essas áreas não são consideradas nem OMECs nem áreas protegidas, visto que tais sítios podem apresentar pouca segurança de resultados em longo prazo se as condições mudarem ou se começarem a permitir atividades prejudiciais ao meio ambiente. managed in ways that achieve positive and sustained long-term outcomes for the in situ conservation of biodiversity, with associated ecosystem functions and services and where applicable, cultural, spiritual, socio-economic, and other locally relevant values". (Decisão 14/8 da CDB.)

Texto original em inglês da UICN (acrescentado pela tradução): "A clearly defined geographical space, recognised, dedicated and managed, through legal or other effective means, to achieve the long-term conservation of nature with associated ecosystem services and cultural values". (Dudley, 2008.) 


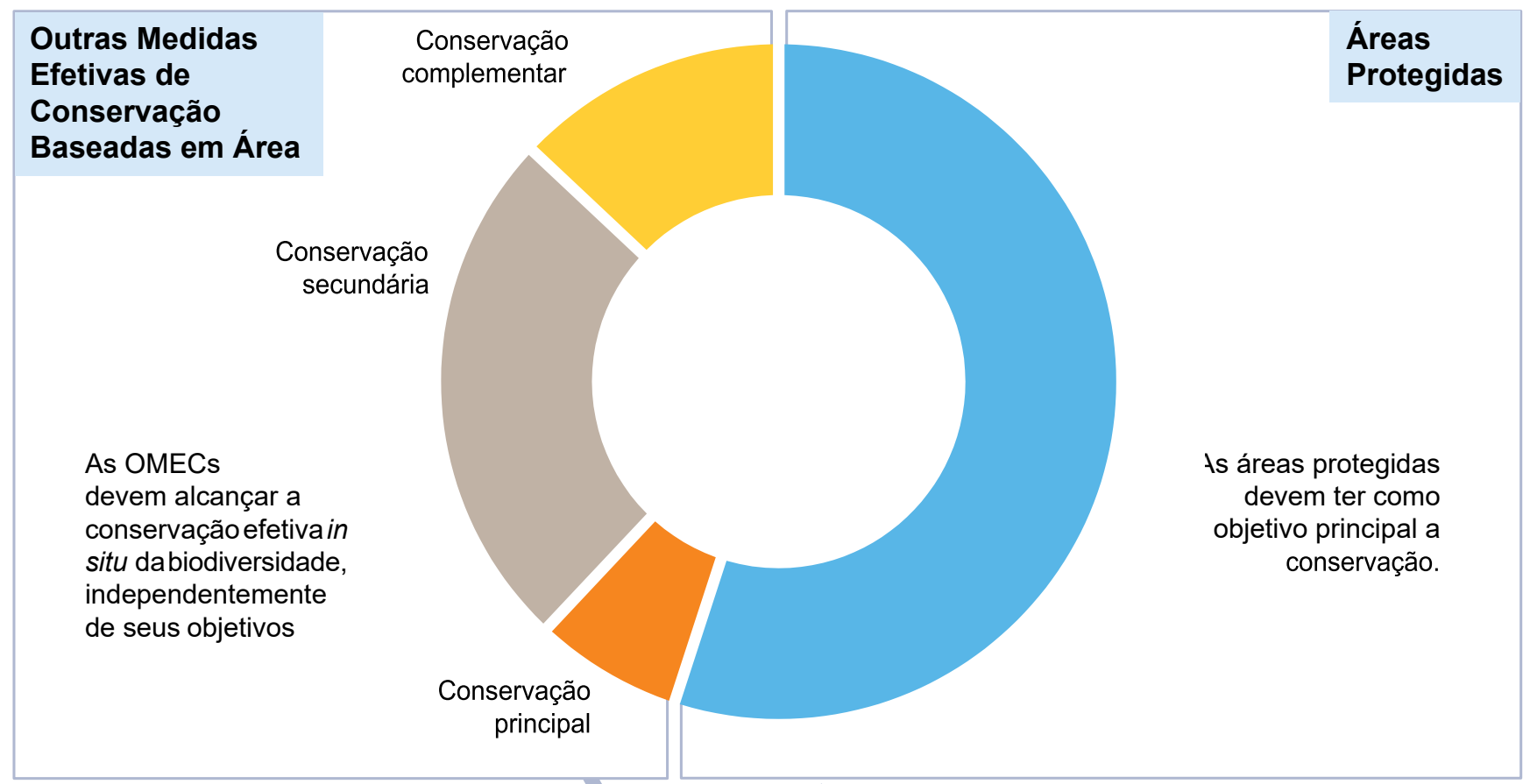

Um sítio com um objetivo principal de conservação pode passar de ser considerado uma OMEC para ser uma área protegida se for reconhecido como tal pela autoridade de governança pertinente.

Figura 1. A relação entre OMECs e áreas protegidas

(Nota: o tamanho dos segmentos é somente ilustrativo e não se baseia em dados reais)

Há várias razões pelas quais as áreas que apresentam resultados importantes de conservação in situ não são reconhecidas nem registradas como áreas protegidas (BorriniFeyerabend \& Hill, 2015), embora possam ser reconhecidas como OMECs por meio de processos de consentimento apropriado - ver Quadro 1. Tanto áreas protegidas como OMECs contribuem para o alcance da Meta 11 de Aichi, mas apresentam uma série de diferenças importantes entre si.

\subsection{Elementos da definição}

As seguintes subseções explicam cada elemento da definição geral de "outras medidas efetivas de conservação baseadas em área":

Uma área geograficamente definida que não seja uma área protegida, que seja governada e gerida de modo a alcançar resultados positivos e sustentáveis em longo prazo para aconservação in situ da biodiversidade, com funções e serviços ecossistêmicos associados e, quando aplicável, com valores culturais, espirituais, socioeconômicos e outros valores localmente relevantes.

Os elementos estão apresentados de acordo com quatro critérios, segundo a Decisão 14/8.

\section{Critério A: A área não é atualmente reconhecida como uma área protegida}

\section{a. "que não seja uma área protegida"}

As OMECs podem contribuir por mérito próprio para o cumprimento de metas baseadas emárea para a conservação terrestre, de água doce e marinha. Isso significa que áreas já designadas como áreas protegidas ou que se encontram dentro destas não deveriam ser reconhecidas nem relatadas como OMECs. Embora áreas protegidas e OMECs se excluam mutuamente, ambas têm valor para a conservação da biodiversidade. Algumas OMECs podem ser reconhecidas como áreas protegidas se, por exemplo, a conservação da natureza se converte em seu objetivo principal de gestão, ou onde a área já cumpre com a definição de uma área protegida e a autoridade de governança solicita seu reconhecimento.

\section{Critério B: A área é governada e gerida}

\section{b. "área geograficamente definida"} Uma área geograficamente definida implica uma área delineada espacialmente com limites acordados e demarcados, que podem incluir áreas terrestres, águas continentais, áreas marinhas e costeiras ou uma combinação destas. Em circunstâncias excepcionais, os limites podem ser definidos por características físicas que se movem com o tempo, tais como as margens dos rios, a marca da maré alta ou a extensão do gelo marinho - ver Quadro 2. 
Quadro 2:

\section{Um olhar mais próximo ao espaço geográfico}

O espaço geográfico tem três dimensões. Isso requer que qualquer regime de governança ou gestão considere, para uma área de duas dimensões, também uma terceira dimensão (vertical) para que toda a diversidade da área seja conservada in situ de modo efetivo. Designações de áreas protegidas ou OMECs frequentemente têm seus limites na terceira dimensão (por exemplo, somente se aplicam até certa profundidade embaixo da terra ou da superfície da água ou têm um limite de altitude para permitir o sobrevoo de aeronaves comerciais). Isso tem sido particularmente controverso nas áreas protegidas marinhas, onde 0 zoneamento vertical para propósitos comerciais prejudica os resultados de conservação, interrompe a conectividade ecológica e cria desafios de monitoramento e de cumprimento da lei. Tanto para as áreas protegidas como para as OMECs, as dimensões de altura e de profundidade precisam ser consistentes com uma gestão efetiva de conservação para proteger a totalidade da biodiversidade nativa.

Consequentemente, a UICN tem uma forte opinião contra o zoneamento vertical das OMECs.

Embora o tamanho das OMECs possa variar, estas devem ser suficientemente grandes para alcançar uma conservação in situ da biodiversidade, incluindo todos os ecossistemas, habitats e espécies de comunidades para os quais a área é importante. "Tamanho suficiente" é altamente contextual e depende das exigências ecológicas para a persistência de espécies e ecossistemas relevantes.

\section{c. "governada"}

Governada implica que a área está sob a autoridade de uma entidade específica ou de uma combinação de entidades sob acordo prévio. As OMECs podem ser governadas sob a mesma gama de tipos de governança de áreas protegidas, a saber:

1. Governança por governos (em váriosníveis);

2 Governança por indivíduos, organizações ou empresas privadas;

3. Governança por povos indígenas ou comunidades tradicionais e locais; e

4. Governança compartilhada (governança conjunta de vários titulares de direitos e partes interessadas)(Dudley, 2008; Borrini-Feyerabend et al., 2017).

Como acontece com as áreas protegidas, a governança das OMECs deve ser equitativa e refletir os princípios de direitos humanos reconhecidos nos instrumentos internacionais e regionais e na legislação nacional, incluindo os de equidade de gênero, povos indígenas e outras comunidades tradicionais e locais. Os mecanismos de governança devem ser efetivos na manutenção da biodiversidade. Qualquer reconhecimento ou relato das OMECs governadas por povos indígenas ou por comunidades tradicionais e locais deve ser baseado na autoidentificação e requero consentimento prévio, livre e informado por parte da(s) autoridade(s) tradicionais de governança (Organização das Nações Unidas, 2007).

\section{d. "gerida"}

Gerida especifica que a área que está sendo gerida para alcançar resultados positivos e sustentáveis de conservação da biodiversidade em longo prazo. As autoridades importantes, os titulares de direitos e as partes interessadas devem ser identificados e envolvidos nagestão.

Ao contrário das áreas protegidas, as OMECs não requerem um objetivo principal de conservação, mas deve existir um vínculo causal direto entre seu objetivo geral e a gestão da área e a conservação in situ da biodiversidade em longo prazo. "Gerida" pode incluir uma decisão deliberada de não intervir na área - ver o exemplo dos naufrágios históricos apresentado no Quadro 3.

A gestão das OMECs deve ser coerente com o enfoque ecossistêmico, ter a habilidade de se adaptar para alcançar os resultados esperados de conservação da biodiversidade em longo prazo eadministrar as novas ameaças emergentes (https://www.cbd.int/ecosystem/). De tal modo, a gestão das OMECs deve incluir "meios efetivos" de controle das atividades que possam impactara biodiversidade, seja através de medidas legais ou outros meios efetivos (tais como leis consuetudinárias ou acordos vinculantes com os proprietários de terras). Na medida do relevante e do possível, a gestão deve ser integrada entre as OMECs e com as áreas circundantes.

Uma área que não tenha um regime de gestão não é uma OMEC, embora sua diversidade permaneça intacta. Por exemplo, áreas não geridas de alto mar, áreas em conflito militar e outras áreas que atualmente encontram-se em estado natural ou quase natural não devem ser consideradas como OMECs se não existir um regime de gestão que proporcione uma conservação in situ efetiva e duradoura (ou em longo prazo) da biodiversidade. Regimes de gestão podem incluir decisões deliberadas de não intervir na área.

\section{Critério C: A área provê uma contribuição sustentável e efetiva para a conservação in situ da biodiversidade}

\section{e. "resultados positivos" para a conservaçãoda biodiversidade (denominados "efetivos", nos critérios da Decisão 14/8 da CDB)}

As OMECs devem ser efetivas na obtenção de resultados positivos e sustentáveis para a conservação in situ da biodiversidade. Especificamente, deve haver uma associação clara entre a gestão e os resultados em relação à biodiversidade, com mecanismos estabelecidos para enfrentar as ameaças existentes ou previsíveis (ver Mathur et al., 2017 para orientações sobre como identificar e gerenciar ameaças).

Nas OMECs não deve haver atividades de nível industrial e implementação de infraestrutura prejudiciais ao meio ambiente. Esse requisito é consistente com a Recomendação 102 da UICN (WCC-2016-Rec-102-EN), adotada no Congresso Mundial para a Conservação de 2016, no Havaí. Tal recomendação insta os governos e autoridades pertinentes a: "adotar e implementar políticas de restrição às atividades de nível industrial e a implementação de infraestrutura prejudiciais ao meio ambiente que possam ter 


\section{Lugares de naufrágios históricos, como o Scapa Flow - um exemplo de conservação complementar}

A proteção estrita de sítios de naufrágios históricos por razões culturais e históricas é uma característica comum em muitas áreas oceânicas ao redor do mundo. Esse propósito, coincidentemente, permite a proteção dos habitats, das espécies e dos ecossistemas marinhos associados. Há numerosos exemplos no Caribe e no Oceano Pacífico que são uma herança de conflitos históricos através dos tempos No Reino Unido, o Scapa Flow talvez seja o exemplo mais conhecido desta "conservação complementar".

O Scapa Flow é um porto natural em frente às Órcades continentais no norte da Escócia. A área está sob a jurisdição da Autoridade Portuária das Ilhas Órcades, cujos objetivos de gestão são uma administração segura do porto e, ao mesmo tempo, a conservação do patrimônio cultural do sítio. A área é reconhecida como túmulo de guerra por conta do naufrágio dos navios de guerra alemães da Primeira Guerra Mundial que foram afundados dento do porto, assim como pelo naufrágio do Royal Oak, o navioalmirante da Marinha Real da Segunda Guerra Mundial, que foi afundado por um submarino alemão.

O Scapa Flow cobre uma área de $324,5 \mathrm{Km} 2$ e contém aproximadamente 1 bilhão de metros cúbicos de água. $A$ proteção estrita outorgada a seus naufrágios históricos também proporciona um alto grau de proteção do ecossistema bentônico, evidenciado pelos abundantes bancos de algas calcárias (ou rodolitos, "maerl beds"), bancos de "escalopes flamejantes" ("flame shell beds"), recifes de "mexilhão-cavalo" ("horse mussel reef") e moluscos de "concha em forma de leque" ("fan shells"), que são muito raros em outros lugares da Escócia. Embora a área não seja gerida com um objetivo específico de conservação da natureza, a proteção da biodiversidade do sítio é alcançada mediante a conservação complementar. Em fevereiro de 2019, o Primeiro-Ministro da Escócia, Nicola Sturgeon, anunciou uma consulta sobre duas novas áreas protegidas marinhas (APMs ou MPAs na sigla em inglês) "históricas" na Escócia, uma delas é o Scapa Flow. Caso seja aprovada, estaria demonstrada a estreita relação entre as OMECs e as áreas protegidas.

impactos negativos em (...) qualquer área de importância particular para a biodiversidade e para os serviços ecossistêmicos que são identificadas pelos governos como essenciais para alcançar as Metas de Aichi para a Biodiversidade". As atividades industriais que causam danos ao meio ambiente incluem, por exemplo, a pesca industrial e a silvicultura ou o manejo florestal de nível industrial, a mineração, a extração de petróleo e gás, a agricultura industrial e a infraestrutura prejudicial ao meio ambiente, tais como represas, estradas e oleodutos. Essas ameaças devem ser evitadas, tanto dentro das OMECs como também nas áreas externas que as afetem.

\section{f. "sustentável em longo prazo"}

Espera-se que a governança e a gestão das OMECs sejam sustentáveis e permitam a conservação efetiva in situ da biodiversidade em longo prazo. Estratégias de gestão em curto prazo ou temporárias não correspondem a uma OMEC. Por exemplo, um período de defeso de pesca comercial que se mantém somente até que se recupere a área de sobrepesca não é uma OMEC. A orientação da UICN é que os fatores de governança e gestão de uma OMEC devem ser contínuos e em longo prazo.

Os resultados efetivos de conservação podem surgir da proteção estrita ou de certas formas de gestão sustentável compatíveis com as definições de "conservação in situ" e de "biodiversidade" da CDB. Contudo, a maioria das áreas geridas para produção de nível industrial, inclusive se apresentarem alguns benefícios para a biodiversidade, não devem ser consideradas como OMECs. A pesca comercia e as atividades florestais comerciais geridas de maneira sustentável, por exemplo, devem ser relatadas com base nas Metas 6 e 7 de Aichi, respectivamente, ou outras metas apropriadas.

Por outro lado, sítios com uma série de enfoques de gestão, incluindo medidas por temporadas, de acordo com as estações (por exemplo, sítios geridos para espécies de aves migratórias), poderão ser qualificados como OMECs, se essas medidas formarem parte de um regime de gestão geral em longo prazo que permita a conservação in situ da biodiversidade durante todo o ano, para a qual o sítio é importante. Em alguns casos, os instrumentos regulatórios em curto prazo, renovados continuamente, podem proporcionar medidas de facto em longo prazo.

A gestão das OMECs deve ser coerente com um enfoque ecossistêmico e preventivo, com capacidade de se adaptar para manter os resultados da biodiversidade em longo prazo e para enfrentar potenciais novas ameaças. Desse modo, medidas práticas devem ser estabelecidas para monitorar e relatar sobre a efetividade das OMECs (ver Seção 4).

\section{g. "conservação in situ da biodiversidade"}

\section{A CDB define conservação in situ em relação à}

biodiversidade, como:

\section{A conservação de ecossistemas e de habitats naturais e a manutenção e recuperação de populações viáveis de espécies em seus ambientes naturais e, no caso de espécies domesticadas ou cultivadas, nos ambientes onde desenvolveram suas propriedades distintas. (Artigo 2 da $C D B.)^{6}$}

As OMECs devem gerar resultados para a conservação da biodiversidade de importância comparável e complementares aos das áreas protegidas. Isso inclui sua contribuição para a representatividade ecológica, a cobertura de áreas importantes para a biodiversidade e as funções e serviços ecossistêmicos associados, a conectividade e a integração em paisagens terrestres e marinhas mais amplas, bem como requisitos de efetividade de gestão e de equidade.

\footnotetext{
$6 \quad$ Texto original em inglês da CDB (acrescentado pela tradução): “'In-situ conservation' means the conservation of ecosystems and natural habitats and the maintenance and recovery of viable populations of species in their natural surroundings and, in the case of domesticated or cultivated species, in the surroundings where they have developed their distinctive properties." (CBD Article 2.)
} 


\section{Um olhar mais atento para a biodiversidade}

As OMECs devem proteger efetivamente um ou mais dos seguintes elementos da biodiversidade nativa:

- Espécies e habitats raros, ameaçados ou em perigo de extinção e os ecossistemas que os sustentam, incluindo espécies e sítios identificados na Lista Vermelha de Espécies Ameaçadas e na Lista Vermelha de Ecossistemas, ambas da UICN, ou seus equivalentes nacionais.

- Ecossistemas naturais representativos.

- Áreas com um alto nível de integridade ecológica ou ecologicamente intactas, caracterizadas pela presença do grupo completo de espécies nativas, e que apoiam os processos ecológicos. Essas áreas estarão intactas ou em processo de restauração sob o sistema de gestão proposto.

- Espécies e ecossistemas com alcance restrito em ambientes naturais.

- Agregações importantes de espécies, inclusive durante a migração ou a desova.

- Ecossistemas especialmente importantes para os estágios de vida das espécies, a alimentação, o descanso, a muda e a reprodução.

- Áreas de importância para a conectividade ecológica ou para interligar uma rede de conservação dentro de uma paisagem terrestre ou marinha.
- Áreas que prestam serviços ecossistêmicos críticos, tais como água limpa e armazenamento de carbono, além de permitir a conservação in situ dabiodiversidade.

- Espécies e habitats importantes para usos humanos tradicionais, tais como plantas medicinais nativas, além de permitir a conservação in situ dabiodiversidade.

Nesse contexto, uma fazenda com uma gestão intensiva, com uma proporção pequena de plantas e aves nativas originais, provavelmente não seria considerada uma OMEC. Pelo contrário, uma área de campos nativos, dominada por plantas nativas e com populações saudáveis de uma grande variedade de aves e mamíferos nativos, poderia ser uma OMEC se tivesse uma gestão de baixa intensidade e o regime de governança garantisse esses resultados em longo prazo. Como nas áreas protegidas, pode haver casos onde uma OMEC é especialmente importante para proteger uma espécie ameaçada, por meio da proteção de todo o ecossistema. À medida que a mudança climática altera os ecossistemas, o entendimento do que é natural e efetivo em um determinado lugar também pode mudar. As OMECs talvez precisem ser reconhecidas e geridas levando em consideração a adaptação à mudança climática (Gross et al., 2016).
Espera-se que as OMECs alcancem a conservação da natureza como um todo, não somente de alguns elementos selecionados da biodiversidade. As definições da CDB de "biodiversidade" e de "conservação in situ" claramente reconhecem que uma única espécie somente pode existir in situ como parte de uma rede interligada com outras espécies e com o ambiente abiótico. Além disso, as medidas de conservação enfocadas em espécies individuais ou subconjuntos de biodiversidade não deveriam pôr em perigo o ecossistema em sua totalidade. Reconhecendo o vínculo entre a diversidade biológica e geológica, a "geodiversidade" também pode ser um importante elemento de atenção para a gestão das OMECs (Zarnetske et al., 2019).

\section{h. "biodiversidade"}

Devido ao vínculo explícito entre as OMECs e os resultados para a conservação da biodiversidade, um requisito claro é que as OMECs devem alcançar a conservação efetiva e sustentável in situ da biodiversidade. Embora os enfoques para identificar os elementos importantes da biodiversidade de tais áreas variem conforme as circunstâncias nacionais, subnacionais e locais, já existe uma orientação global para identificar as KBAs (UICN, 2016) e para descrever áreas como os sítios Ramsar e as EBSAs (Dunstan, 2016). A biodiversidade conservada por uma OMEC pode ocorrer em áreas dentro e fora da jurisdição nacional.

O reconhecimento de uma OMEC deve incluir a identificação dos atributos da biodiversidade para os quais o sítio é considerado importante e basear-se no conhecimento mais completo à disposição (ver Quadro 4). Esses valores chave da biodiversidade, assim como os valores de conservação das OMECs, devem ser descritos e monitorados ao longo do tempo.

\section{Critério D: Funções e serviços ecossistêmicos associados e valores culturais, espirituais, socioeconômicos e outros valores relevantes em nível local}

\section{i. "Funciones y servicios de los ecosistemas"}

Los ecosistemas saludables y funcionales proporcionan una serie de servicios. Por un lado, las funciones de los ecosistemas son parte integral de la biodiversidad y son definidos como los procesos biológicos, geoquímicos y físicos que ocurren dentro de un ecosistema. Por otro, los servicios ecosistémicos incluyen servicios de provisión como alimentos y agua; servicios de regulación de inundaciones, sequías, degradación de tierras y enfermedades, y servicios de soporte, como la formación de suelos y el reciclaje de nutrientes. La protección de estas funciones y estos servicios ecosistémicos es un motivo frecuente para reconocer a una OMEC como tal. Sin embargo, la gestión para mejorar un servicio ecosistémico determinado no debe tener un impacto negativo en los valores generales de conservación de la biodiversidad del área.

\section{j. "Valores culturales, espirituales, socioeconómicos y otros valores relevantes anivel local"}

Las OMEC incluyen áreas en las que es posible proteger especies y hábitats clave y manejar la biodiversidad como parte de prácticas y valores culturales, espirituales, socioeconómicos y otros valores relevantes a nivel local. En estos casos, es esencial garantizar el reconocimiento y la protección de los vínculos entre la diversidad biológica y cultural y las prácticas de gobernanza y gestión asociadas, de modo que se consigan resultados positivos para la biodiversidad, como su uso sostenible tradicional (Artículo 10.c. del CDB). Es importante, sin embargo, que la gestión de estos valores en una OMEC no tenga un impacto negativo en la conservación de la biodiversidad. 


\section{Identificar outras medidas efetivas de conservação baseadas em área na prática}

A conservação in situ da biodiversidade é "fundamental" para deter a perda da biodiversidade (CDB, 1992). As áreas protegidas e as OMECs são os meios principais para alcançar a conservação in situ com base na Meta 11 de Aichi e continuarão sendo importantes elementos para o cumprimento das metas da CDB pós-2020. Todosos esforços para conservar a biodiversidade são valiosos, mas somente as medidas baseadas em área que contribuam diretamente para a conservação in situ em longo prazo devem ser consideradas para se relatar com base nas metas de conservação como a Meta 11 de Aichi. Outros esforços de conservação, incluindo os enfoques baseados em áreas destinadas ao uso sustentável, são mais apropriadamente relatados com base em outros tipos de metas, tais como as Metas 6 (pesca sustentável) e 7 de Aichi (manejo florestal, silvicultura e agricultura sustentáveis) ou outras metas análogas pós-2020 (ver, por exemplo, Laffoley et al., 2017 ou Anexo I). A identificação e a documentação das OMECs contribuirão para que qualquer meta da CDB busque a conservação in situ, incluindo a Meta Aichi 11 e as metas para a conservação in situ adotadas pós-2020.

Para apoiar os processos de tomada de decisões, a CMAP desenvolveu um instrumento simples de triagem em quatro etapas, diretamente vinculado à definição e à explicação de seus termos na Seção 2. Qualquer área em processo de consideração para ser reconhecida como uma OMEC deve, primeiramente, ter avaliada sua elegibilidade com base nesses critérios e contar com o consentimento da autoridade de governança.

\subsection{Instrumento de triagem}

O instrumento de triagem (ver Quadro 5) consta de quatro testes para determinar se uma área reúne os requisitos para ser uma candidata a OMEC.

- Teste 1. Assegure-se que a área não esteja reconhecida nem registrada como uma área protegida (stricto sensu).

- Teste 2. Assegure-se que a área cumpra com as características essenciais para ser uma OMEC.

- Teste 3. Assegure-se que o resultado da conservação perdurará em longo prazo.

- Teste 4. Assegure-se que relatar como uma meta de conservação in situ baseada em área (por exemplo, a Meta 11 de Aichi), em oposição a um objetivo de uso sustentável, seja o enfoque correto.

Os elementos de cada teste estão apresentados na Seção 3.2. Uma área deve passar nos quatro testes de triagem para ser considerada uma candidata a OMEC.
Quadro 5:

\section{Usando o instrumento de triagem - pontos chave a tratar}

Há sete pontos importantes a considerar quando aplicamos o instrumento de triagem:

1. Para os casos em que a autoridade de governança dirija o processo - incluindo potenciais OMECs governadas por povos indígenas e comunidades tradicionais e locais, a quem se aplica o princípio de consentimento prévio, livre e informado -, confirmar o interesse da autoridade de governança de que a área seja avaliada e potencialmente relatada como uma OMEC.

2 Ler atentamente e analisar as diretrizes e os critérios de triagem e reunir uma equipe de revisão formada por pessoas familiarizadas com a variedade dos enfoques implementados na escala de trabalho para a conservação espacial nesse lugar.

3. Antes da aplicação do instrumento de triagem (Seção 3.2), compilar um abrangente conjunto de mapas e informações sobre possíveis lugares que poderiam qualificar como uma OMEC e compará-los com mapas de áreas protegidas designadas ou propostas conhecidas de modo que a relação seja facilmente entendida.

4. Aplicar os quatro testes de triagem para cada área a ser avaliada como uma OMEC.

5. Identificar as áreas que passam ou aprovam nos quatro testes como candidatas a OMECs e avaliálas usando um instrumento de avaliação empírica adaptada em nível nacional (Seção 3.3).

6. Relatar as OMECs que passaram no processo de avaliação para o WDPA - ver Seção 4.

7. Para aquelas áreas que não passaram os testes, registrar as razões dessa decisão segundo cada critério. Essa informação pode ser útil para identificar se, com uma mudança na governança ou na gestão, tal área poderia qualificar como uma OMEC. Sendo assim, aplicar novamente os pontos acima de 1-5, se for o caso. 


\subsection{Aplicação do instrumento de triagem}

Esta seção explica como se deve aplicar o instrumento de triagem. Todas as referências aos "elementos" remetem aos componentes da definição, descrito na Seção 2.2.

Teste 1. Assegure-se que a área não esteja reconhecida ou relatada como área protegida.

A área não está reconhecida nem proposta como área protegida marinha, de água doce nem terrestre (ver elemento a).

Teste 2. Assegure-se que a área cumpra com as caraterísticas definidas para as OMECs.

1. Localização: A área deve ser um espaço geograficamente definido. As medidas mais amplas para espécies ou meio ambiente que não sejam "baseadas em área" reprovam neste teste. Por exemplo, as proibições ou regulações nacionais ou regionais de caça para uma espécie específica, regras para o avistamento de baleias ou períodos de defeso (ver elemento b) são medidas regionais específicas para cada espécie e não uma conservação in situ baseada em área.

2 Governança e gestão sustentáveis: A área está governada e gerida e espera-se que esses arranjos sejam contínuos e sustentáveis em longo prazo. Deve existir um vínculo causal direto entre eles: (i) a governança, o(s) objetivo(s) e a gestão geral da área e (ii) a conservação in situ da biodiversidade em longo prazo. As áreas em que não exista uma autoridade de governança, nem de gestão, não são consideradas OMECs (ver elementos c, $\mathbf{d}$ ef). Portanto, uma área que está atualmente em um estado natural ou quase natural não é automaticamente uma OMEC.

3. Conservação efetiva in situ da biodiversidade: $A$ área oferece uma conservação efetiva in situ da biodiversidade, com funções e serviços ecossistêmicosassociados.

Deve haver um entendimento claro que que a área está conservando efetivamente sua biodiversidade nativa e processos ecossistêmicos que apoiam a biodiversidade. Isso pode ser alcançado mediante diversos tipos de governanças e práticas de gestão, incluindo aquelas associadas com os valores culturais, espirituais, socioeconômicos e outros relevante em nível local. As áreas que produzem resultados de conservação somente por um curtos período ou áreas que têm a intenção ou o potencial de conservar a natureza, mas que ainda não produzem resultados para a conservação, não qualificam como OMECs (ver elementos $\mathbf{e}, \mathbf{g}, \mathbf{h}, \mathbf{i}$ e j).

4. A área está livre de atividades prejudiciais ao meio ambiente e as ameaças à biodiversidade podem ser geridas de acordo com os sistemas de governança e gestão existentes.

Teste 3. Assegure-se que o resultado da conservação perdure em longo prazo.

Isso se refere à probabilidade de que o resultado para a conservação se mantenha em longo prazo através de meios legais ou outros efetivos (como leis consuetudinárias ou acordos formais com os proprietários das terras - ver elementos e e f). Este teste enfatiza a diferença entre esforços de conservação, que podem ser revertidos facilmente, e os de uma OMEC, que deve manter os resultados de conservação em longo prazo.

Test 4. Assegure-se que relatar com base em uma meta de conservação in situ baseada em área (por exemplo, a Meta 11 de Aichi), em contraposição a uma meta de uso sustentável, seja o enfoque correto.

A conservação in situ da biodiversidade é um dos três objetivos principais da $\mathrm{CDB}$. Dentro do contexto de relato à $\mathrm{CDB}, \mathrm{com}$ base nas Metas de Biodiversidade de Aichi de 2020, as áreas protegidas e as OMECs são os meios principais para alcançar uma conservação in situ e o foco principal da Meta 11 de Aichi. Como se explica no Quadro 6, as medidas baseadas em área também podem ser aplicadas para alcançar o uso sustentável dos componentes da biodiversidade (por exemplo, o enfoque da Meta 6 de Aichi sobre pescas sustentáveis e a Meta 7 de Aichi sobre agricultura, aquicultura e manejo florestal e silvicultura sustentáveis). Ainda assim, é importante não confundir tais medidas com medidas de conservação in situ da Meta 11 de Aichi. Depois de 2020, continuará sendo importante relatar as medidas de conservação in situ (áreas protegidas e OMECs) e as medidas de uso sustentável com base em suas metas apropriadas, respectivamente. Ver Anexo I, sobre a relação entre a Meta 11 e outras metas associadas, e o Anexo II, para ver uma árvore de decisão sobre a seleção da Meta de Aichi mais apropriada para uma determinada medida de conservação.

As áreas que aprovem nesses quatro testes podem ser consideradas como candidatas a OMECs.

\subsection{Avaliação}

Áreas consideradas candidatas a OMECs devem, então, estar sujeitas a uma revisão mais detalhada, incluindo evidências empíricas, e conduzidas caso a caso. A Metodologia de Avaliação da OMEC está disponível para download no seguinte link: https://www.iucn.org/theme/protected-areas/ wcpa/what-we-do/oecms.

Somente se deve reportar ao WDPA (ver Seção 4 e Anexo III) aquelas áreas que passem nessa avaliação empírica e tenham o consentimento pleno e efetivo e participação da autoridade de governança.

\subsection{Exemplos de OMECs potenciais}

As áreas das situações abaixo descritas podem ser consideradas como OMECs potenciais. Esses exemplos cobrem distintos tipos de governança, com o fim de ilustrar sua aplicabilidade. Os exemplos marcados com um asterisco 
Quadro 6:

\section{Assegure-se que a Meta 11 de Aichi seja o enfoque correto}

O Plano Estratégico sobre Biodiversidade 2011-2020 e as 20 Metas de Biodiversidade de Aichi requerem um conjunto amplo de enfoques para frear a perda da biodiversidade, incluindo a tomada de consciência sobre a biodiversidade, a eliminação de incentivos perversos que promovem a sua degradação, a implementação de planos de produção sustentáveis, a redução de perda de habitats, a prevenção da extinção de espécies, a redução de pressões diretas sobre a biodiversidade em níveis sustentáveis e a conservação in situ da biodiversidade.

As medidas de conservação baseadas em área podem contribuir para o alcance de várias Metas de Aichi, mas nem todas elas alcançam seus objetivos mediante a conservação in situ da biodiversidade de acordo com os critérios da Meta 11.

Por exemplo, muitos períodos de defeso da pesca aplicam $a$ áreas geográficas específicas e, consequentemente, são medidas baseadas em área, mas somente proíbem-se a pesca de determinadas espécies de peixes comerciais que estão exauridas, o uso de certos tipos de artes de pesca que prejudicam o habitat ou que não são seletivas ou a pesca durante determinadas épocas do ano, quando as espécies em risco estão presentes e em uma etapa de vida vulnerável (por exemplo, agregações de desovas). Eles podem continuar a permitir atividades pesqueiras e não pesqueiras (por exemplo, provas sísmicas, perfuração petroleira) sempre que essas atividades não comprometerem os propósitos para os quais foram estabelecidas. Como tal, podem ser instrumentos efetivos para ajudar a garantir que as pescas sejam geridas sustentavelmente (objetivo da Meta 6 de Aichi), sem alcançar uma conservação in situ da biodiversidade (objetivo da Meta 11 de Aichi).
Do mesmo modo, os planos de manejo florestal são aplicados em áreas e podem variar em seus graus de impacto ecológico. Os enfoques de menor impacto podem conservar mais espécies, estruturas de habitats e funções ecossistêmicas do que enfoques de alto impacto e alguns, de fato, alcançam o significado de "uso sustentável" da CDB - por exemplo, o uso de componentes de diversidade biológica de uma maneira e em um ritmo que não impliquem declínio de diversidade biológica em longo prazo. Contudo, devido aos impactos extrativos que alteram seu ecossistema (sobretudo em casos dessa atividade em nível industrial), eles talvez não possam alcançar uma conservação in situ de toda a biodiversidade. Tais medidas, nesse caso, devem ser melhor consideradas como contribuições para a Meta 7 de Aichi, cujo propósito é que as áreas florestais sejam manejadas de maneira sustentável até2020.

O limite entre uma medida vinculada à Meta 7 e à Meta 11 pode ser difícil de se determinar em casos de usos consuetudinários de recursos biológicos em ambientes naturais extensos por parte dos povos indígenas e comunidades tradicionais e locais. Em tais casos, pode ser útil avaliar o grau de proteção dessas áreas perante as ameaças florestais e não florestais em longo prazo para determinar se uma área é uma OMEC.

Outras Metas de Aichi para as quais se podem utilizar com frequência medidas baseadas em área são a Meta 10 (reduzir ao mínimo as múltiplas ameaças antropogênicas sobre os recifes de coral), a Meta 12 (prevenir a extinção e melhorar o estado de conservação de espécies ameaçadas), a Meta 14 (restaurar e salvaguardar ecossistemas que prestam serviços essenciais) e a Meta 15 (conservar e restaurar ecossistemas degradados). Somente onde essas medidas alcançarem seus objetivos mediante a conservação in situ da biodiversidade em longo prazo, também poderão contribuir para a Meta 11. $\left(^{*}\right)$ podem ser encontrados em uma edição especial da revista PARKS sobre OMECs (CMAP-UICN, 2018, https://doi. org/10.2305/UICN.CH.2018.PARKS-24-SI.en).

\section{Conservação principal}

Um sítio que tem como objetivo principal a conservação e que resulta em uma conservação efetiva da biodiversidade, mas que não está relatado como uma área protegida, pode ser reconhecido como uma OMEC se a autoridade de governança assim o desejar.

\section{Exemplos:}

- Alguns territórios ou áreas (marinhas, de água doce ou terrestres) governados por povos indígenas, comunidades tradicionais e locais ou entidades privadas que têm como objetivo principal e explícito a conservação e que realizam a conservação in situ da biodiversidade, mas nos quais o corpo de governança deseja que os territórios ou áreas sejam reconhecidos e relatados como OMECs e não como áreas protegidas.
- Áreas de conservação privadas, geridas com um objetivo de conservação específico, mas que não são reconhecidas como áreas protegidas pela legislação nacional (Mitchell et al., 2018), como, por exemplo, as áreas de restauração de ecossistemas na Indonésia (Utomo \& Walsh, 2018*).

- Áreas que incluem KBAs, cuja gestão permite a conservação in situ da biodiversidade em longo prazo mediante, por exemplo, a regulação ou outros enfoques efetivos.

- A retirada permanente de algumas áreas de produção de florestas manejadas, como as florestas mais antigas primárias ou outras de alto valor para a biodiversidade, protegidas das ameaças florestais e não florestais.

- Algumas áreas naturais geridas por universidades para a pesquisa biológica.

\section{Conservação secundária:}

\section{Exemplos:}

- Territórios e áreas conservados por povos indígenas ou comunidades tradicionais e locais (TICCAs, ou partes destas

10 | Reconhecer e relatar outras medidas efetivas de conservação baseadas em área 
áreas) para manter ecossistemas naturais ou quase naturais, com baixos níveis de uso de recursos naturais, implementados de modo sustentável e que não degradem a biodiversidade da área. Incluem áreas costeiras e marinhas, onde as práticas locais de colheita e gestão realizadas pela comunidade resultam na conservação de facto de populações de peixes, habitats e outra biodiversidade marinha associada, como algumas áreas marinhas geridas localmente (LMMAs) (ver Jupiter et al., 2014).

- Sistemas de gestão tradicionais que mantêm níveis altos de biodiversidade associada. Este poderiam incluir certos sistemas de gestão agrícola ou florestal que mantêm as espécies nativas e seu habitat (ver Eghenter, 2018; Mwamidi et al., 2018*).

- Parques urbanos ou municipais geridos principalmente para recreação pública, mas que são suficientemente grandes e em estados natural como para alcançar a conservação in situ da biodiversidade (por exemplo, pastagem selvagem, zonas húmidas) e cuja gestão mantém estes valores de biodiversidade (ver Gray et al., 2018).

- Terras e águas militares ou porções de terras e águas militares, cujo principal propósito de gestão é a defesa, mas com objetivos secundários específicos centrados na conservação da biodiversidade. O Canadá propôs, em 2019, que se considerassea Base Shilodas Forças Canadenses, localizada no ecossistema de pradaria de campos mistos do centro-sul de Manitoba (Canadá), como uma OMEC

- Bacias hidrográficas ou outras áreas geridas principalmente para a gestão dos recursos hídricos que também resulta na conservação in situ da biodiversidade. Estas incluem, por exemplo, prados aquáticos, florestas ribeirinhas, florestas costeiras, zonas húmidas, córregos, bacias de terras altas ou outras áreas geridas para a estabilização de solos e encostas em longo prazo, mitigação de inundações ou outros serviços ecossistêmicos (ver Matallana-Tobón et al., 2018*).

- Áreas com períodos de defeso permanentes ou longos, concebidas para proteger ecossistemas completos para recrutamento de estoques, para proteger ecossistemas especializados em sua totalidade ou para proteger espécies em perigo mediante a conservação in situ da biodiversidade em seu conjunto, e que têm demonstrado ser igualmente efetivas contra as ameaças pesqueiras e não pesqueiras.

- Reservas de caça que mantêm habitats naturais, flora e fauna, bem como populações viáveis de espécies nativas, sejam ou não de interesse de caça.

- Áreas restauradas com sucesso a partir de ecossistemas degradados ou ameaçados, que proporcionam serviços ecossistêmicos importantes e que também contribuem para a conservação efetiva da biodiversidade, por exemplo, zonas húmidas de água doce ou costeiras restauradas para proteção contra inundações.

- Áreas que contribuem para a conservação devido a seu papel na conectividade de áreas protegidas e outras áreas de particular importância para a conservação da biodiversidade, contribuindo, assim, para a viabilidade em longo prazo de ecossistemas mais extensos (ver Waithaka \& Warigia Njoroge, 2018*).

\section{Conservação complementar}

\section{Exemplos:}

- Sítios naturais sagrados com altos valores de biodiversidade que se conservam em longo prazo devido a seus vínculos com um ou mais grupos religiosos (ver Matallana-Tobón et al., 2018*).

- Áreas costeiras e marinhas protegidas por motivos distintos aos da conservação, mas que alcançam a conservação in situ da biodiversidade como, por exemplo, naufrágios históricos, túmulos de guerra etc. (ver Quadro 3).

- Terras e águas militares ou porções de terras e águas cujo propósito de gestão é a defesa e não têm como objetivo secundário a conservação, mas alcançam a conservação efetiva da biodiversidade em longo prazo.

\subsection{Exemplos de áreas que provavelmente não cumprem com oscritérios}

\section{É improvável que as seguintes áreas e regimes de gestão se classifiquem como OMECS:}

- Áreas pequenas e seminaturais dentro de uma paisagem gerida intensivamente, com um valor limitado para a conservação da biodiversidade, como parques municipais, jardins institucionais ou domésticos, arboretos, margens dos campos, beiras das estradas, sebes, costas estreitas ou retrocessos da linha de costa, corta-fogos, praias recreativas, marinas e campos de golfe.

- Florestas manejadas comercialmente (de nível industrial) para o fornecimento de madeira e destinadas à exploração madeireira, apesar de poderem ter alguns valores de conservação e poderem apoiar a conservação de certas espécies de interesse. As contribuições dessas áreas devem ser consideradas para a Meta 7 de Aichi.

- Períodos de defeso e outros instrumentos de gestão depescalocalizados espacialmente, incluindo, mas não limitados a quotas de pesca ou limites de capturas, reservas temporais ou áreas de restrição a artes de pesca relacionadas com uma única espécie, grupo de espécies ou com foco no habitat, as quais podem ser sujeitas a exploração periódica ou consideradas para fins de gestão de estoques, e que não promovem a conservação in situ dos ecossistemas, dos habitats e nem das espécies associadas às espécies focais. Taisáreas devem ser consideradas paraa Meta 6 de Aichi.

- Terras agrícolas cuja gestão limita a conservação in situ da biodiversidade. Podem incluir, por exemplo, pastagens que são usadas de maneira intensiva que não permitem manter os ecossistemas ou as espécies nativas, ou pastagens replantadas com monoculturas ou espécies não nativas para fins de produção de gado.

- Áreas reservadas fora de produção, pousio de verão e mudanças mantidas mediante subvenções para práticas agrícolas que podem beneficiar a biodiversidade. 
- Medidas de conservação que se aplicam a uma única espécie ou a um grupo de espécies, em uma ampla gama geográfica como regulações de caça ou regras para o avistamento de baleias e que correspondem a medidas mais amplas de conservação de espécies (Metas 5, 6, 7 ou 12).

Os exemplos acima não pretendem ser exaustivos ou contemplar todos os casos possíveis, mas indicar quais tipos de áreas podem qualificar como OMECS e quais não. Ao se considerar alguma área, as definições e critérios aplicados no teste de triagem de quatro critérios será o caminho apropriado para garantir a identificação consistente das candidatas a OMECs. Devido à diversidade de contextos nos que se encontram as OMECs, é essencial que todas as áreas sejam analisadas cuidadosamente para avaliar cada caso específico.

O conceito de OMEC será geralmente utilizado para reconhecerexemplos de conservaçãoefetiva baseadaemárea e regimes de governança e gestão que os viabilizem. Contudo, o conceito também poderia ser utilizado para promover esforços novos e adicionais em prol da conservação. Durante a negociação da Decisão 14/8 da CDB, termos qualificativos como "ter um valor relevante para a diversidade biológica ou ter objetivos para alcançá-la" "e "alcançar, ou esperam-se alcançar resultados positivos e sustentáveis para a conservação in situ da biodiversidade" foram adicionados às diretrizes para a identificação das OMECs. Os governos que propuseram as ressalvas enfatizaram que as incluíram para considerar os sítios nos quais se estava fazendo restauração, em um reconhecimento das tentativas intencionais de recuperação dos ecossistemas. A intenção de restaurarecossistemas e habitats é louvável, mas áreas de restauração não devem ser reconhecidas como OMECs até que não se obtenham resultados demonstráveis e relevantes de biodiversidade - ver Quadro 7.

\subsection{Direitos e}

\section{responsabilidades das autoridades degovernança}

Há diversas razões para que uma autoridade de governança considere o reconhecimento de sua área como OMEC, podendo identificar uma área como uma possível OMEC e avaliá-la por si mesma ou buscar apoio independente para determinar se a mesma qualifica como OMEC mediante essas diretrizes. A autoridade de governança tem o direito de se opor à nomeação ou ao reconhecimento externos de sua área como OMEC em casos nos quais o consentimento não tenha sido dado. Isso aplica para os quatro tipos de governança, como foi indicado anteriormente (ver elemento c). Quando uma área é reconhecida como OMEC, recai sobre a autoridade de governança uma maior responsabilidade de governar e gerir a área de modo que alcance a conservação in situ da biodiversidade.

\subsection{Apoio às outras medidas efetivas de conservação baseadas em área}

O reconhecimento das OMECs deve ser apoiado por medidas que melhorem a capacidade de governança de suas legítimas autoridades e assegurem resultados positivos e sustentáveis para a biodiversidade. Embora as circunstâncias nacionais possam diferir, qualquer legislação relacionada deve proporcionar maior apoio e reconhecimento aos sistemas de governança existentes e não tentar suplantar ou alterar desnecessariamente os arranjos locais efetivos.

\section{Quadro 7}

\section{Restauração ecológica nas outras medidas efetivas de conservação baseadas em área}

Restauração ecológica é o processo de gestão ou de contribuição para a recuperação de um ecossistema degradado, danificado ou destruído como um meio de manter sua resiliência ecossistêmica e conservar a biodiversidade (CDB, 2016). É provável que se torne um instrumento de conservação mais comum e necessário no futuro.

Áreas propostas para ou sob esforços ativos de restauração não devem ser reconhecidas como OMECs até que obtenham resultados demonstráveis e relevantes para a biodiversidade. Portanto, a orientação da UICN é que para as de áreas de restauração possam qualificar como OMEC, devem cumprir com as seguintes condições:

1. A restauração está sendo realizada em um ecossistema de alto valor para a biodiversidade (ver Quadro 4) de modo que a área, uma vez restaurada, qualificará como OMEC em virtude de seu valor de conservação e de sua contribuição ao fortalecimento das redes de áreas protegidas existentes;

2. Os esforços de restauração devem (i) reduzir as ameaças que causaram a degradação original e a perda da biodiversidade, (ii) mostrar uma recuperação bem-sucedida do ecossistema baseada nos princípios da restauração ecológica e (iii) contribuir em longo prazo para a manutenção de um ecossistema resiliente e em evolução; e

3. Demonstração de restauração ecológica ativa ou regeneração natural de tipo e em escala que se espera que recuperem e mantenham a integridade ecológica e o conjunto total de espécies. 


\section{Monitorar e relatar outras medidas efetivas de conservação baseadas em área}

\begin{abstract}
É necessário monitorar a efetividade das OMECs. Isso deve incluir: (i) linha de base, com documentos que a demonstrem, e monitoramento contínuo dos valores da biodiversidade desses sítios; (ii) monitoramento e mapeamento participativos e contínuos, pela ou com a comunidade, e incorporação do conhecimento tradicional, se pertinente; (iii) monitoramento das ações de conservação, incluindo aquelas enfocadas na manutenção da biodiversidade e no melhoramento da conservação in situ; e (iv) monitoramento da governança, envolvimento dos atores interessados e sistemas de gestão que contribuam para a obtenção dos resultados em prol da biodiversidade (Haase et al., 2018; Woodley et al., 2015).
\end{abstract}

Um elemento chave da definição é que as OMECs devem ser "governadas e geridas de modo que alcancem resultados positivos e sustentáveis de biodiversidade em longo prazo". Isso se relaciona com o conceito de efetividade de gestão. Além disso, o monitoramento e o relato sobre a efetividade das OMECs serão fundamentais para garantir que os sítios continuarão obtendo resultados para a conservação (Woodley et al., 2015). A medição da efetividade de gestão de áreas protegidas (PAME) será, em muitos casos, a forma mais pragmática de medir a efetividade das OMECs, mas os instrumentos PAME devem estar amparados por informação quantitativa adicional sobre os resultados da biodiversidade. Usar o padrão da Lista Verde de Áreas Protegidas e Conservadas da UICN contribuirá ainda mais ao suporte de tal documentação (UICN, 2017). As autoridades de governança responsáveis pelas OMECs devem garantir o monitoramento adequado da efetividade de gestão para assegurar resultados de conservação em longo prazo (ver Hockings et al., 2015). Essa informação também deverá ser relatada ao WCMCPNUMA para sua integração no Banco de Dados Mundial de Efetividade de Gestão de Áreas Protegidas (GD-PAME).

O conceito de OMEC é um produto das decisões das Partes signatárias da CDB. Ao adotar a definição de OMECs, a COP 14 da CDB também estimulou as Partes a que enviem dados sobre OMECs para o WDPA gerido pelo WCMC-PNUMA (CDB, 2018). A fim de cumprir com essa obrigação, o WCMC-PNUMA estabeleceu um banco de dados paralelo para OMECs no âmbito da iniciativa "Protected Planet", para complementar o WDPA. A iniciativa "Protected Planet" abarca várias bancos de dados que se podem acessar e fazer download, www.protectedplanet. net. O WCMC-PNUMA usa os dados desses bancos para medir os avanços com base nos objetivos internacionais de conservação, como a Meta 11 de Aichi sobre Biodiversidade e os ODS's 14 e 15.

As medidas baseadas em área que se classificam como áreas protegidas ou OMECs devem ser relatadas ao WDPA e ao banco de dados de OMECs, respectivamente. Tal relato deve ser feito com o consentimento prévio, livre e informado das autoridades de governança relevantes ou pertinentes.

Para mais informação sobre os requisitos de como relatar ao WDPA e ao banco de dados de OMECs e sobre a verificação de dados, ver Tabela 1 (abaixo), Anexo III e as orientações disponiveis em www.wcmc.io/oecm guidance.

Tabela 1. Princípios básicos para a verificação de dados para inclusão nos bancos de dados do "Protected Planet"

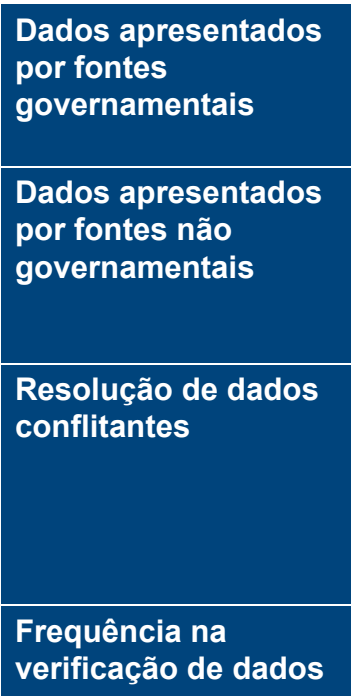

Em conformidade com os mandatos oficiais do WDPA, os dados apresentados pelas fontes governamentais sobre as áreas protegidas ou OMECs serão considerados verificados pelo país e serão incluídos no WDPA e no banco de dados de OMECs depois de ajustes de formato e de controle de qualidade.

Os dados recebidos de provedores não governamentais se submetem a um processo de verificação antes de ser incluídos nos bancos de dados do "Protected Planet".

A informação pode ser revisada por verificadores governamentais ou especialistas. Se nenhuma das partes for capaz de verificar os dados, esses não serão ingressados nos bancos de dados do "Protected Planet".

Quando existir um conflito entre as opiniões do provedor e o verificador de dados (por exemplo, desacordos sobre o limite correto de um sítio), isso será discutido com ambas as partes para chegar a uma solução.

Os provedores serão informados sobre o processo de verificação ao apresentar os dados e serão informados sobre seu avanço. Nos casos em que não for possível encontrar uma solução, os dados não poderão ser ingressados nos bancos de dados do "Protected Planet".

verificação de dados

O WCMC-PNUMA pretende atualizar todos os dados pelo menos uma vez a cada cinco anos.

Para consultas sobre como relatar, por favor, contate: protectedareas@unep-wcmc.org. 


\section{Referências}

Borrini-Feyerabend, G., N. Dudley, T. Jaeger, B. Lassen, N. Pathak Broome, A. Phillips e T. Sandwith (2017).

Governança de Áreas Protegidas: da compreensão à ação. Série Diretrizes para melhores Práticas para Áreas Protegidas, No. 20, Gland, Suiça: UICN. xvi + 124pp. https://portals.iucn.org/library/node/46934

Borrini-Feyerabend, G. and Hill, R. (2015). 'Governance for the conservation of nature', in Worboys, G. L., Lockwood, M., Kothari, A., Feary, S. and Pulsford, I. (eds) Protected Area Governance and Management, pp. 169-206. ANU Press: Canberra.

Canada Department of Fisheries and Oceans (2016). Operational guidance for identifying "other effective area-based conservation measures" in Canada's marine environment. Canada Department of Fisheries and Oceans: Ottawa, Canada. 9pp. Accessed January 17, 2017 at:

http://www.dfo-mpo.gc.ca/oceans/documents/publications/ oeabcm-amcepz/2016_11_24_OEABCM-marine-guidancefor-public-audience_Version-1b.pdf

Convention on Biological Diversity (CBD) (1992). Convention on Biological Diversity. https://www.cbd.int/convention/text/

CBD (2010). Strategic Plan on Biodiversity 2011-2020. https://www.cbd.int/sp/

CBD (2012). Decision on Protected Areas (XI/24). https:// www.cbd.int/doc/decisions/cop-11/cop-11-dec-24-en.pdf

CBD (2016). Progress Towards the Achievement of Aichi Biodiversity Targets 11 and 12 (Decision XIII/2). https://www. cbd.int/doc/decisions/cop-13/cop-13-dec-02-en.pdf

CBD (2016). Ecosystem restoration: short-term action plan. CBD/COP/DEC/XIII/5, 10 December 2016. https://www.cbd. int/doc/decisions/cop-13/cop-13-dec-05-en.pdf

CBD (2018). Protected areas and other effective area-based conservation measures (Decision 14/8). https://www.cbd.int/ doc/decisions/cop-14/cop-14-dec-08-en.pdf

CBD (2019). Post-2020 Global Biodiversity Framework: Discussion Paper. https://www.cbd.int/doc/c/d431/ b38f/3d580bb73e7c2b5aaa286310/post2020-prep-01-01-en.pdf

Day, J., Dudley, N., Hockings, M., Holmes, G., Laffoley, D., Stolton, S. and Wells, S. (2012). Guidelines for applying the IUCN Protected Area Management Categories to Marine Protected Areas. IUCN: Gland, Switzerland. https://portals. iucn.org/library/node/10201

Donald, P., Buchanan, G.M., Balmford, A., et al. (2019). 'The prevalence, characteristics and effectiveness of Aichi Target 11- s "other effective area-based conservation measures" (OECMs) in Key Biodiversity Areas'. Conservation Letters.

2019; e12659. https://doi.org/10.1111/conl.12659

Dudley, N. (ed.) (2008). Guidelines for Applying Protected Area Management Categories. IUCN: Gland, Switzerland. 86pp.

Dunstan, P. K., Bax, N.J., Dambacher, J.M., Hayes, K.R., Hedge, P.T., Smith, D.C., and Smith, A.D.M. (2016). 'Using ecologically or biologically significant marine areas (EBSAs) to implement marine spatial planning'. Ocean \& Coastal Management, 121, 116-127.
Eghenter C. (2018). 'Indigenous effective area-based conservation measures: conservation practices among the Dayak Kenyah of North Kalimantan'. PARKS 24. IUCN: Gland https://doi.org/10.2305/IUCN.CH.2018.PARKS-24-SICE.en

Gray, M. (2004). Geodiversity: Valuing and Conserving Abiotic Nature. John Wiley and Sons: UK.

Gray, P.A., Cheriton, D., Gaetz, N., Lehman, P., Sherwood, J., Beechey, T. J. and Lemieux C.J. (2018). 'Comparing screening tools for assessment of potential 'other effective area-based conservation measures' in Ontario, Canada'. PARKS 24. IUCN: Gland. https://doi.org/10.2305/IUCN.CH.2018.PARKS24-SIPAG.en

Gross, J.E., Woodley, S., Welling, L.A., and Watson, J. (eds.) (2016). Adapting to Climate Change: Guidance for protected area managers and planners. Best Practice Protected Area Guidelines Series No. 24. IUCN: Gland, Switzerland.

Haase, P., Tonkin, J.D., Stoll, S., Burkhard, B., Frenzel, M., Geijzendorffer, I.L., Häuser, C. et al. (2018). 'The next generation of site-based long-term ecological monitoring: Linking essential biodiversity variables and ecosystem integrity'. Science of the Total Environment 613: 1376-1384.

Indigenous Circle of Experts, (2018). We Rise Together: Achieving Pathway to Canada Target 1 through the creation of Indigenous Protected and Conserved Areas in the spirit and practice of reconciliation. Indigenous Circle of Experts, Pathway to Canada Target 1.

Hockings, M., Leverington, F. and Cook, C. (2015).

'Protected area management effectiveness', in Worboys, G. L., Lockwood, M., Kothari A., Feary S. and Pulsford I. (eds) Protected Area Governance and Management. ANU Press, Canberra.

IUCN (2016). A Global Standard for the Identification of Key Biodiversity Areas. First edition. IUCN: Gland, Switzerland. https://portals.iucn.org/library/node/46259

IUCN (2017). Green List of Protected and Conserved Areas Standard. https://www.iucn.org/theme/protected-areas/ourwork/iucn-green-list

IUCN/WCPA (2018). Special Issue on "Other Effective Areabased Conservation Measures". PARKS 24. IUCN: Gland. https://doi.org/10.2305/IUCN.CH.2018.PARKS-24-SI.en

Jonas, H., Barbuto, V., Jonas, H.C., Kothari, A. and Nelson, F. (2014). 'New steps of change: looking beyond protected areas to consider other effective area based conservation measures'. PARKS 20 (2): 111-128. htps://doi.org/10.2305/ IUCN.CH.2014.PARKS-20-2.HDJ.en

Jonas, H. and MacKinnon, K. (eds.) (2016). Co-Chairs'Report of the First Meeting of International Experts of the Task Force on Other Effective Area-based Conservation Measures. IUCNWCPA: Gland, Switzerland. https://www.iucn.org/theme/ protected-areas/wcpa/what-we-do/oecms

Jonas, H. and MacKinnon, K. (eds.) (2016). Advancing Guidance on Other Effective Area-based Conservation Measures: Report of the Second Meeting of the IUCN-WCPA Task Force on Other Effective Area-based Conservation Measures. IUCN: Gland, Switzerland. https://www.iucn.org/ theme/protected-areas/wcpa/what-we-do/oecms 
Jonas, H. and MacKinnon, K. (eds.) (2017). Using Case Studies to Enhance Guidance on Other Effective Area-based Conservation Measures: Report of Third Meeting of the IUCNWCPA TaskForce on OtherEffective Area-based Conservation Measures. IUCN-WCPA: Gland, Switzerland. https://www. iucn.org/theme/protected-areas/wcpa/what-we-do/oecms

Jonas, H. and Sandwith, T. (eds.) (2019). Towards Recognising, Reporting and Supporting OECMs: Report of the Fourth Expert Meeting of the IUCN-WCPA Task Force on Other Effective Area-based Conservation Measures. IUCN: Gland, Switzerland. https://www.iucn.org/theme/protectedareas/wcpa/what-we-do/oecms

Jonas, H., MacKinnon, K., Dudley, N., Hockings, M., Jessen, S., Laffoley, D., MacKinnon, D., Matallana-Tobón, C., Sandwith, T., Waithaka J. and Woodley, S. (2018). 'Other effective area-based conservation measures:From Aichi Target 11 to the post-2020 Biodiversity Framework'. PARKS 24. IUCN: Gland. https://doi.org/10.2305/IUCN. CH.2018.PARKS-24-SIHDJ.en

Jupiter, S., Cohen, P., Weeks, R., Tawake, A. and Govan, H. (2014). 'Locally-managed marine areas: Multiple objectives and diverse strategies'. Pacific Conservation Biology 20. 10.1071/PC140165.

Laffoley, D., Dudley, N., Jonas, H., MacKinnon, D., MacKinnon, K., Hockings, M. and Woodley, S. (2017). 'An introduction to "other effective area-based conservation measures" under Aichi Target 11 of the Convention on Biological Diversity: origin, interpretation and some emerging ocean issues'. Journal of Aquatic Conservation 27 (Supplement 1): 130-137.

Leverington, F., Lemos Costa, K., Courrau, J., Pavese, H., Nolte, C., Marr, M., Coad, L., Burgess, N., Bomhard, B. and Hockings, M. (2010). Management effectiveness evaluation in protected areas-a global study, Second edition. The University of Queensland Brisbane, Australia.

Lopoukhine, N. and Dias, B.F. (2012). 'Editorial: What does Target 11 really mean?' PARKS 18 (1):5-8.

MacKinnon, D., C.J. Lemieux, K. Beazley, S. Woodley, R. Helie, J. Perron, J. Elliott, C. Haas, J. Langlois, H. Lazaruk, T. Beechey, and P. Gray (2015). 'Canada and Aichi Biodiversity Target 11: understanding "other effective areabased conservation measures" in the context of the broader target'. Biodiversity and Conservation 24 (14): 3559-3581. DOI 10.1007/s10531-015-1018-1.

Matallana-Tobón, C., Santamaría, M., Areiza Tapias, A., Solano C. and Galán S. (2018). 'Rethinking nature conservation in Colombia: a case study of other effective area-based conservation measures'. PARKS24. IUCN: Gland. https://doi.org/10.2305/IUCN.CH.2018.PARKS-24-SICLM.en

Mathur, V. B., Onial, M. and Mauvais, G. (2015) "Managing threats", in G. L. Worboys, M. Lockwood, A. Kothari, S. Feary and I. Pulsford (eds). Protected Area Governance and Management, pp. 473-494, ANU Press, Canberra.

Mitchell, B., Fitzsimons, J., Stevens, C. and Wright, D. (2018). 'PPA or OECM? Differentiating between privately protected areas and other effective area-based conservation measures on private land'. PARKS 24. IUCN: Gland. https://doi. org/10.2305/IUCN.CH.2018.PARKS-24-SIBAM.en
Mwamidi, D.M., Renom, J.G. Fernández-Llamazares, Á., Burgas, D., Domínguez, P. and Cabeza, M. (2018). 'Contemporary pastoral commons in East Africa as OECMs: a case study from the Daasanach community'. PARKS 24. IUCN: Gland. https://doi.org/10.2305/IUCN.CH.2018.PARKS24-SIDMM.en

UNEP-WCMC and IUCN (2016). Protected Planet Report 2016. UNEP-WCMC and IUCN: Cambridge UK and Gland, Switzerland. https://portals.iucn.org/library/ node/46261

UNEP-WCMC, 2017. World Database on Protected Areas User Manual 1.5. UNEP-WCMC: Cambridge, UK. Available at: http://wcmc.io/WDPA Manual

UNEP-WCMC and IUCN (2018). Protected Planet Report 2018. UNEP-WCMC and IUCN: Cambridge UK and Gland, Switzerland. https://portals.iucn.org/library/ node/48344

UNEP-WCMC (2018). 2018 United Nations List of Protected Areas. Supplement on protected area management effectiveness. UNEP-WCMC: Cambridge, UK.

United Nations (2007). United Nations Declaration on the Rights of Indigenous Peoples. Available at: https://www. un.org/development/desa/indigenouspeoples/wp-content/ uploads/sites/19/2018/11/UNDRIP E web.pdf

Utomo, A.B. and Walsh T.A. (2018). 'Hutan Harapan ecosystem restoration concession, Sumatra, Indonesia: a potential OECM?' PARKS 24. IUCN: Gland. https://doi. org/10.2305/IUCN.CH.2018.PARKS-24-SIABU.en

Waithaka, J. and Warigia Njoroge, G. (2018). 'The role of potential OECMs in safeguarding space for nature in Kenya: $A$ case study of wildlife conservancies'. PARKS 24. IUCN: Gland. https://doi.og/10.2305/IUCN.CH.2018.PARKS-24-SIJMW.en

Watson, James EM, Nigel Dudley, Daniel B. Segan, and Marc Hockings. 'The performance and potential of protected areas'. Nature 515, no. 7525 (2014): 67.

Woodley, S., Bertzky B., Crawhall, N., Dudley, N., Miranda Londoño, J., MacKinnon, K., Redford, K.R. and Sandwith, T. (2012). 'Meeting Aichi Target 11: What does success look like for protected area systems?' PARKS 18 (1): 23-36. https:// doi.org/10.2305/IUCN.CH.2012.PARKS-18-1.SW.en

Woodley, S., MacKinnon, K., McCanny, S., Pither, R., Prior, K. Salafsky, N. and Lindenmayer, D. (2015). 'Managing protected areas for biological diversity and ecosystem functions', in Worboys, G.L., Lockwood, M., Kothari, A., Feary, S. and Pulsford, I. (eds.) Protected Area Governance and Management, pp. 651-684, ANU Press, Canberra. http://press. anu.edu.au/wpcontent/uploads/2015/02/CHAPTER21.pdf

Zarnetske, P.L., Read, Q.R., Record, S., Gaddis, K.D., Pau, S., Hobi, M.L., Malone, S.L., Costanza, J., Dahlin K.M., Latimer A.M., Wilson, A.M., Grady, J.M., Ollinger, S.V. and Finley A.O. (2019). 'Towards connecting biodiversity and geodiversity across scales with satellite remote sensing'. Ecological Soundings.https://doi.org/10.1111/geb.12887 


\section{Anexo I}

\section{A ampla relação entre as \\ Metas de Aichi e a Meta 11}

(Adaptado de Laffoley et al., 2017).

\begin{tabular}{|c|c|c|}
\hline Meta ${ }^{7}$ & Texto & Relação com a Meta 11 \\
\hline Meta 3 & $\begin{array}{l}\text { Até } 2020, \text { no mais tardar, incentivos, incluindo } \\
\text { subsídios, que sejam prejudiciais à biodiversidade } \\
\text { terão sido eliminados, descontinuados ou } \\
\text { reformados para minimizar ouevitar impactos } \\
\text { negativos, enquanto que incentivos positivos para } \\
\text { o uso sustentável da biodiversidade e para sua } \\
\text { conservação terão sido desenvolvidos e aplicados, } \\
\text { devendo ser consistentes e estar em conformidade } \\
\text { com a Convenção e com outras obrigações } \\
\text { internacionais, levando-se em consideração as } \\
\text { condições socioeconômicas nacionais. }\end{array}$ & $\begin{array}{l}\text { Incentivos positivos para o uso sustentável da biodiversidade e para } \\
\text { sua conservação que resultem em conservação in situ da natureza } \\
\text { baseada em área, tais como incentivos fiscais para donos de áreas } \\
\text { conservadas de forma privada, são exemplos de medidas vinculadas à } \\
\text { Meta } 3 \text { e que também contribuem para o alcance da Meta } 11 \text {. }\end{array}$ \\
\hline Meta 4 & $\begin{array}{l}\text { Até } 2020 \text {, no mais tardar, governos, empresas } \\
\text { e partes interessadas em todas as esferas terão } \\
\text { tomado medidas ou implementado planos } \\
\text { para alcançar uma produção e um consumo } \\
\text { sustentáveis, além de terem mantido os impactos } \\
\text { vinculados ao uso de recursos naturais claramente } \\
\text { dentro de limites ecológicos seguros. }\end{array}$ & $\begin{array}{l}\text { Planos de produção sustentável (medidas vinculadas à Meta 4) podem } \\
\text { incluir áreas reservadas fora de produção que constituam áreas de } \\
\text { referência não exploradas, áreas "asseguradas" ou áreas de "fontes de } \\
\text { obtenção de sementes", o que ajuda a garantir o uso sustentável de } \\
\text { uma área mais ampla. Se tais áreas forem efetivas para a conservação } \\
\text { in situ em longo prazo da biodiversidade, elas podem contribuir para a } \\
\text { Meta } 11 .\end{array}$ \\
\hline Meta 5 & $\begin{array}{l}\text { Até } 2020 \text {, a taxa de perda de todos os habitats } \\
\text { naturais, incluindo florestas, terá sido reduzida } \\
\text { ao menos pela metade e, na medida do possível, } \\
\text { levada praticamente a zero, e a degradação e } \\
\text { a fragmentação terão sido significativamente } \\
\text { reduzidas. }\end{array}$ & $\begin{array}{l}\text { O estabelecimento de áreas vinculadas à Meta } 11 \text { é uma forma } \\
\text { importante para se alcançar a Meta } 5 \text {. Estabelecer áreas efetivas para } \\
\text { a conservação da natureza in situ em longo prazo, sejam elas áreas } \\
\text { protegidas ou OMECs, pode evitar a perda de habitats naturais, além } \\
\text { da degradação e da fragmentação de ecossistemas, sobretudo se } \\
\text { tais áreas forem bem geridas. Em um contexto terrestre, isso pode se } \\
\text { relacionar a florestas primárias e, em um contexto marinho, pode vir a } \\
\text { ser particularmente válido no caso de habitats como recifes de coral, } \\
\text { pastos marinhos e montes submarinos. }\end{array}$ \\
\hline Meta 6 & $\begin{array}{l}\text { Até } 2020 \text {, todos os estoques de peixes } \\
\text { e invertebrados, assim como de plantas } \\
\text { aquáticas, serão manejados e capturados } \\
\text { de maneira sustentável, legal e segundo } \\
\text { abordagens ecossistêmicas de forma a evitar } \\
\text { a sobre-exploração, aplicar planos e medidas } \\
\text { de recuperação voltados a todas as espécies } \\
\text { exauridas, impedir que a pesca provoque } \\
\text { impactos adversos significativos sobre espécies } \\
\text { ameaçadas e sobre ecossistemas vulneráveis } \\
\text { e fazer com que os impactos da pesca sobre } \\
\text { estoques, espécies e ecossistemas estejam } \\
\text { dentro de limites ecológicos seguros. }\end{array}$ & $\begin{array}{l}\text { Áreas vinculadas à Meta } 11 \text { podem ajudar a garantir a exploração } \\
\text { sustentável dos elementos da biodiversidade da paisagem marinha } \\
\text { mais ampla das seguintes formas: fornecendo parâmetros a } \\
\text { partir dos quais avaliar os efeitos das decisões de gestão; instituir } \\
\text { funções de "seguro" e de "fonte de obtenção de sementes" } \\
\text { para permitir a recuperação de falhas de gestão; ou concedendo } \\
\text { benefícios de "transbordamento" na paisagem marinha mais ampla. } \\
\text { Medidas de conservação de espécies ou habitats que se apliquem } \\
\text { extensivamente em paisagens marinhas mais amplas ao invés de } \\
\text { áreas geográficas específicas e bem definidas e que não estejam } \\
\text { estabelecidas em longo prazo devem apontar para a Meta } 6 \text {. O } \\
\text { uso sustentável de recursos biológicos pode ser um objetivo de } \\
\text { certas áreas vinculadas à Meta } 11 . \text { A diferença fundamental entre } \\
\text { medidas baseadas em área vinculadas à Meta } 11 \text { e à Meta } 6 \text { é o } \\
\text { fato de que áreas vinculadas à Meta } 11 \text { alcançam a conservação } \\
\text { in situ da natureza como um todo, não podendo tal resultado ser } \\
\text { comprometido por usos permitidos. }\end{array}$ \\
\hline Meta 7 & $\begin{array}{l}\text { Até } 2020 \text {, áreas de agricultura, aquicultura e } \\
\text { silvicultura serão geridas de forma sustentável, } \\
\text { garantindo a conservação da biodiversidade. }\end{array}$ & $\begin{array}{l}\text { Áreas vinculadas à Meta } 11 \text { inseridas em paisagens terrestres geridas } \\
\text { principalmente para fins de agricultura, aquicultura ou manejo } \\
\text { florestal ou silvicultura podem ajudar a garantir que tais atividades } \\
\text { não causem perda irreversível de biodiversidade em paisagens } \\
\text { terrestres mais amplas ao prover parâmetros a partir dos quais é } \\
\text { possível avaliar os efeitos de decisões de gestão. Podem também } \\
\text { prover funções de "seguro" e de "fonte de obtenção de sementes" } \\
\text { para permitir a recuperação de falhas de gestão, conceder benefícios } \\
\text { de "transbordamento" (com benefícios além da área específica) e } \\
\text { contribuir para a conectividade na paisagem terrestre mais ampla. }\end{array}$ \\
\hline
\end{tabular}


Meta 9 Até 2020, espécies exóticas invasoras e seus vetores terão sido identificadose priorizados, espécies prioritárias terão sido controladas ou erradicadas e medidas para o controle de vetores terão sido tomadas de forma a evitar sua introdução e seu estabelecimento.

Meta 10 Até 2015, as múltiplas pressões antropogênicas sobre recifes de coral e outros ecossistemas vulneráveis por mudança climática ou por acidificação oceânica terão sido minimizadas de forma a manter sua integridade e seu funcionamento. Até 2020, a extinção de espécies ameaçadas conhecidas terá sido evitada e sua situação de conservação, sobretudo daquelas em maior declínio, terá sido melhorada e mantida.

Áreas vinculadas à Meta 11 que possuam objetivos de gestão visando a manutenção ou a restauração da integridade ecológica podem ser um foco para medidas vinculadas à Meta 9 que buscam erradicar espécies exóticas.

Medidas vinculadas à Meta 11 podem ajudar a proteger recifes de coral e outros ecossistemas vulneráveis de pressões antropogênicas, tais como degradação de habitat e sobre-exploração de espécies. No entanto, medidas vinculadas à Meta 11 não podem, sozinhas, combater ameaças advindas de mudança climática ou acidificação oceânica, as quais requerem reduções dos gases do efeito estufa em âmbito global.

Medidas que contribuem com a Meta 11 constituem um enorme
instrumento para prevenir a extinção e colaborar com a recuperação de espécies ameaçadas através da conservação in situ em longo prazo de espécies e seus ecossistemas associados. Medidas vinculadas à Meta 12 e que se concentrem em uma única espécie, não sejam baseadas em área, não sejam de longo prazo e não sejam alcançadas por meio da conservação in situ da biodiversidade como um todo, não se enquadram na Meta 11. Medidas vinculadas com a Meta 11 podem prevenir a extinção e colaborar com a recuperação de espécies ameaçadas, contribuindo assim também para a Meta 12. Até 2020, ecossistemas que forneçam serviços essenciais, incluindo serviços relacionados à água, e que contribuam para a saúde, para os meios de vida e para o bem-estar terão sido restaurados e salvaguardados, levando-se em conta as necessidades das mulheres, das comunidades indígenas e locais e das pessoas pobres e vulneráveis.

Até 2020 , a resiliência ecossistêmica e a contribuição da biodiversidade para as reservas de carbono terão sido ampliadas por meio de ações de conservação e de restauração, incluindo a restauração de pelo menos $15 \%$ dos ecossistemas degradados, contribuindo assim para a mitigação e adaptação à mudança climática e para o combate à desertificação.

\section{Medidas vinculadas à Meta 11 podem ajudar a alcançar a Meta} 14 por meio da proteção de ecossistemas que fornecem diversos serviços. Certas medidas que visam o alcance da Meta 14 podem também ser reconhecidas como contribuições para a Meta 11, caso sejam obtidas por meio da conservação in situ da biodiversidade, independentemente de seus objetivos principais. Em um contexto marinho, isso pode significar a manutenção de recifes de coral ou manguezais como parte da proteção do litoral contra o impacto de ondas e tempestades, por exemplo.

Áreas vinculadas à Meta 11 são frequentemente mais resilientes, mais diversas e armazenam mais carbono devido a seus níveis geralmente mais altos de integridade ecológica em comparação com paisagens terrestres e marinhas já exploradas. Proteger áreas intactas e proteger e restaurar áreas degradadas são duas formas através das quais as medidas vinculadas à Meta 11 podem contribuir também para a Meta 15. Medidas vinculadas à Meta 15 e que alcancem seus objetivos através da conservação in situ da biodiversidade em longo prazo podem ser reconhecidas como áreas que contribuem para o alcance da Meta 11.
Até 2020 , os conhecimentos tradicionais, as inovações e as práticas de comunidades indígenas e locais relevantes para a conservação e para o uso sustentável da biodiversidade, assim como sua utilização consuetudinária de recursos biológicos, serão respeitados, de acordo com legislações nacionais e obrigações internacionais relevantes, e plenamente integrados e refletidos na implementação da Convenção por meio da participação total e efetiva de comunidades indígenas e locais em todas as esferas relevantes.
Medidas vinculadas à Meta 11 podem contribuir para a Meta 18 ao ajudar a garantir que áreas nas quais conhecimentos tradicionais, inovações e práticas de comunidades indígenas, tradicionais e locais tenham se desenvolvido, e onde se dê sua utilização consuetudinária de recursos biológicos, permaneçam ecologicamente intactas e capazes de sustentar tais atividades em longo prazo. Em contrapartida, certas áreas indígenas tradicionalmente geridas podem contribuir para a Meta 11, como sítios naturais sagrados, ainda que não sejam parte da rede formal de áreas protegidas. 


\section{Anexo II}

\section{Apoio à tomada de decisões: A Meta 11 de Aichi é a mais apropriada para avaliar uma medida de conservação?}

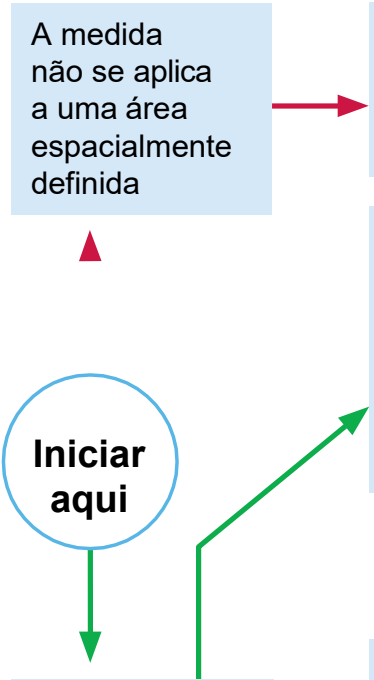

A medida se aplica a uma área espacialmente definida
Não é uma medida vinculada à Meta 11. Avaliar se a mesma contribui para outras Metas de Aichi, se pertinente

A medida visa principalmente salvaguardar ecossistemas, espécies e diversidade genética, melhorando assim o estado da biodiversidade (Objetivo

C, Plano Estratégico de Biodiversidade 2011-2020)

A medida visa principalmente reduzir as pressões diretas sobre a biodiversidade e assegurar que o uso de componentes da biodiversidade ocorra de um modo e em um ritmo que não acarretem seu declínio em longo prazo (Objetivo B, Plano Estratégico de Biodiversidade 2011-2020)

A medida visa principalmente aumentar os benefícios para todos a partir da biodiversidade e dos serviços ecossistêmicos (Objetivo D, Plano Estratégico de Biodiversidade 2011-2020)

Independentemente de seus objetivos principais, a medida conserva de maneira efetiva ecossistemas e habitats e mantém ou recupera populações viáveis de espécies em seus meios naturais

A medida não tem por objetivo nem conserva de maneira efetiva ecossistemas e habitats e tampouco mantém ou recupera populações viáveis de espécies em seus meios naturais
A medida já é ou poderia ser reconhecida como uma área protegida

A medida visa principalmente conservar ecossistemas e habitats e manter ou recuperar populações viáveis de espécies em seus meios naturais (potencial OMEC vinculada à Meta 11 de Aichi)

A medida visa principalmente evitar a extinção e melhorar e manter o estado de conservação de espécies ameaçadas conhecidas (medida potencial vinculada à Meta 12 de Aichi)

A medida visa principalmente manter a diversidade genética de plantas cultivadas e animais criados e domesticados, além de variedades silvestres, incluindo outras espécies de valor socioeconômico e cultural (medida potencial vinculada à Meta 13 de Aichi)

A medida visa principalmente reduzir ou deter a perda, a degradação e a fragmentação de habitats naturais (medida potencial vinculada à Meta 5 de Aichi)

A medida visa principalmente garantir que o manejo e a captura de peixes marinhos, invertebrados e plantas sejam sustentáveis (medida potencial vinculada à Meta 6 de Aichi)

A medida visa principalmente garantir que áreas de agricultura, aquicultura, manejo florestal ou silvicultura sejam sustentáveis (medida potencial vinculada à Meta 7 de Aichi)

A medida visa principalmente minimizar múltiplas pressões antropogênicas sobre recifes de coral e outros ecossistemas vulneráveis impactados por mudança climática ou por acidificação oceânica de forma a manter sua integridade e seu funcionamento (medida potencial vinculada à Meta 10 de Aichi)

A medida visa principalmente restaurar e salvaguardar ecossistemas que fornecem serviços essenciais, incluindo aqueles relacionados à água, além de contribuir para a saúde, para as subsistências e para o bem-estar (medida potencial vinculada à Meta 14 de Aichi)

A medida visa principalmente aumentar a resiliência ecossistêmica e a contribuição da biodiversidade para os estoques de carbono através da conservação e da restauração, incluindo a restauração de ecossistemas degradados (medida potencial vinculada à Meta 15 de Aichi)

Avaliar como potencial OMEC vinculada à Meta 11 e se a mesma contribui para outras Metas Aichi, se pertinente

Não é uma medida vinculada à Meta 11. Avaliar se a mesma contribui para outras Metas Aichi, se pertinente 
Relatar como área protegida vinculada à Meta 11 e avaliar sua contribuição para outras metas, se pertinente

A medida alcança seus objetivos por meio da conservação de ecossistemas e habitats e da manutenção ou recuperação de populações viáveis de espécies em seus meios naturais

A medida não alcança seus objetivos por meio da conservação de ecossistemas e habitats e da manutenção ou recuperação de populações viáveis de espécies em seus meios naturais
Avaliar como OMEC potencial vinculada à Meta 11 e se a mesma contribui para outras metas, se pertinente

Avaliar como OMEC potencial vinculada à Meta 11 e se a mesma contribui para as Metas 12, 13 ou outras, se pertinente

Não é uma medida da Meta 11. Avaliar se a mesma contribui para as Metas 12, 13 ou outras, se pertinente
A medida alcança seus objetivos por meio da conservação integral de ecossistemas e habitats e da manutenção ou recuperação de populações viáveis de espécies em seus meios naturais

A medida não alcança seus objetivos por meio da conservação integral de ecossistemas e da manutenção ou recuperação de populações viáveis de espécies em seus meios naturais
Avaliar como OMEC potencial vinculada à Meta 11 e se a mesma contribui para as Metas 5,6 , 7,10 ou outras, se pertinente

Não é uma medida vinculada à Meta 11. Avaliar se a mesma contribui para as Metas 5, 6, 7, 10 ou outras, se pertinente
A medida alcança seus objetivos por meio da conservação de ecossistemas e habitats e da manutenção ou recuperação de populações viáveis de espécies em seus meios naturais

A medida não alcança seus objetivos por meio da conservação de ecossistemas e habitats e da manutenção ou recuperação de populações viáveis de espécies em seus meios naturais
Avaliar como OMEC potencial vinculada à Meta - 11 e se a mesma contribui para as Metas 14 , 15 ou outras, se pertinente

Não é uma medida vinculada à Meta 11. Avaliar se a mesma contribui para as Metas 14, 15 ou outras, se pertinente

\begin{tabular}{|l} 
LEGENDA \\
Verde: Via principal para avaliação como medida \\
potencial vinculada à Meta 11 de Aichi \\
Amarelo: Via secundária para avaliação como \\
medida potencial vinculada à Meta 11 de Aichi \\
(requer mais evidencia/fundamentação) \\
Vermelho: Não constitui via para avaliação como \\
medida potencial vinculada à Meta 11 de Aichi
\end{tabular}




\section{Anexo III}

\section{Banco de Dados Mundial de Áreas Protegidas}

\section{Bancos de Dados do Portal "Protected Planet" de Áreas Protegidas e OMECs}

Todos os dados sobre outras medidas efetivas de conservação baseadas em área (OMECs ou áreas conservadas) devem ser enviados ao Centro para Monitoramento da Conservação Mundial da ONU Ambiente (WCMC-PNUMA) para serem incluídos no Banco de Dados Mundial de Áreas Protegidas (WDPA).

Orientações adicionais estão disponíveis em: www.wcmc.io/conservedareas guidance

\section{O que é o Banco de Dados MundialdeÁreasProtegidas?}

O WDPA é o banco de dados mundial mais abrangente de áreas protegidas marinhas e terrestres, contendo tanto dados espaciais (por exemplo, limites e pontos) como dados de atributos associados (por exemplo, tabelas) coletados de forma normalizada. Informações de origem também são mantidas para todos os conjuntos de dados enviados. O WDPA é atualizado mensalmente e disponibilizado para consulta e download através do Protected Planet, com exceção de dados que contenham restrições de compartilhamento estabelecidas por seus provedores. $O$ Manual do Usuário do WDPA (WCMC-PNUMA, 2017) fornece informações detalhadas e orientações sobre os dados nele contidos, incluindo sua compilação e normas de dados.

O novo banco de dados de OMECs segue a mesma estrutura do WDPA, com pequenas modificações. O WDPA e os bancos de dados de OMECs são as fontes de dados oficiais utilizadas em diversos mecanismos mundiais para a realização de relatórios, informando indicadores e acompanhando o progresso em relação às metas referentes a áreas protegidas e conservadas, incluindo as Metas de Aichi para a Biodiversidade do Plano Estratégico da CDB e os Objetivos de Desenvolvimento Sustentável da ONU(ODS's).

\section{Relato, coleta de dados e validação de Áreas Protegidas e OMECs}

Normalmente, os dados são encaminhados ao WDPA ou ao banco de dados de OMECs pela autoridade de governança da área protegida ou conservada, tendo prioridade em relação aos demais dados enviados sobre a mesma área oriundos de outras fontes. Quando for impossível à autoridade fornecer atualizações devido à falta de capacidade, falta de dados ou outras circunstâncias, ela poderá sugerir outro provedor para o fornecimento de atualizações. Todos os sítios devem corresponder às definições de área protegida ou de OMEC estabelecidas pela UICN e pela CDB.

Somente uma versão de cada área protegida ou conservada será armazenada nos bancos de dados do "Protected Planet". Em caso de áreas sobrepostas, geralmente se trata de designações diferentes aplicadas ao mesmo espaço geográfico.

Todos os dados do WDPA ou do banco de dados de OMECs devem obedecer a um conjunto de norma de dados. Tais normas são importantes para garantir que toda informação seja fornecida dentro de um formato comum interoperável e aplicável a uma ampla variedade de propósitos informativos e analíticos. Existem quatro requisitos chave que devem ser obedecidos para cumprir com as normas de dados do "Protected Planet":

1. Todos os sítios devem corresponder às definições de área protegida ou de OMEC estabelecida pela UICN e pela CDB.

2 Devem-se fornecer dados espaciais de sistemas de informação geográfica (SIGs) e uma lista associada de atributos normalizados.

3. Deve-se também fornecer a origem da informação para garantir que a propriedade dos dados se encontre preservada e seja rastreável.

4. Deve-se assinar um acordo de fornecimento de dados para garantir que haja uma comprovação por escrito na qual o fornecedor dos dados aceite a inclusão destes no WDPA ou no banco de dados de OMECs e os termos que definem sua disponibilização.

\section{Utilização dos bancos de dados do "Protected Planet" para medir o progresso com base nas Metas}

\begin{abstract}
O WCMC-PNUMA utiliza dados do "Protected Planet" para medir o progresso dos objetivos internacionais de conservação, tais como a Meta 11 de Aichi. Para relatar com base na Meta 11, três estatísticas serão geradas para os níveis nacional, regional e global:
\end{abstract}

- Cobertura de área protegida;

- Cobertura de OMEC; e

- Cobertura combinada. 
Para calcular a cobertura, o WCMC-PNUMA remove as sobreposições entre os sítios e exclui certas categorias de sítios (os propostos, os pontos sem área relatada e as reservas da biosfera que fazem parte do Programa Homem e Biosfera da UNESCO). Ainda que as áreas conservadas e as áreas protegidas normalmente não ocupem a mesma área (ver Seção 3.2 b), podem existir eventuais sobreposições. Em tais casos, a área de sobreposição é tratada somente como uma área protegida, evitando-se a dupla contagem. Mais informações sobre como o WCMC-PNUMA calcula as estatísticas de cobertura estão disponíveis em https:// protectedplanet.net/c/calculating-protected-area-coverage

\section{Monitoramento de outras medidas efetivas de conservação baseadas em área}

\begin{abstract}
A Efetividade de Gestão de Áreas Protegidas (PAME) é, em muitos casos, a forma mais pragmática de se avaliar a eficácia de áreas conservadas, especialmente se os instrumentos PAME estiverem amparados por informações adicionais sobre os resultados da biodiversidade. Mais de 40 instrumentos foram desenvolvidos para avaliações PAME (ver WCMCPNUMA, 2018). A adoção dos sistemas PAME existentes significa que será mais fácil para a autoridade de governança relatar o monitoramento da efetividade ao WCMC-PNUMA e que as avaliações terão um formato padronizado entre os sítios e ao longo do tempo.
\end{abstract}

Alguns princípios básicos para monitorar as áreas conservadas para acompanhar a conservação efetiva se encontram descritos nos passos 1-4 abaixo. Os passos 1-3 podem também ser utilizados como embasamento para decidir se um sítio é uma área conservada ou se ainda se encontra efetivamente conservado após sucessivas avaliações.

1. Descrever todos os valores de biodiversidade significativos do sítio e registrar as origens da informação para servirem de embasamento. Considerar a representatividade, o estado intacto, o contexto da paisagem, as espécies e os habitats raros, ameaçados, endêmicos ou significativos e a integridade ecológica.

2. Identificar as pressões e as ameaças ao sítio que impactarão os valores da biodiversidade.

3. Revisar as contribuições de gestão e medidas aplicadas ao sítio para avaliar sua efetividade, se são suficientes para manter os atributos da biodiversidade e se abarcam totalmente o objetivo da biodiversidade no sítio, além de se ocupar de ameaças controláveis à conservação in situ da biodiversidade.
4. Revisar a efetividade em termos de resultados de conservação do sítio através da medição do estado dos atributos prioritários, estabelecendo e revisando metas e indicadores para medir estados e tendências ao longo do tempo, avaliando a mitigação das ameaças e monitorando e realizando a gestão de maneiraflexível.

O procedimento para relatar ao Banco de Dados Mundial de Efetividade de Gestão de Áreas Protegidas (GD-PAME), gerido pelo WCMC-PNUMA, segue uma abordagem similar àquela descrita acima para o WDPA e para o banco de dados de OMECs. Em caso de dúvidas a respeito do relato, compilação, uso e processamento do GD-PAME, favor contatar: protectedareas@unep-wcmc.org 




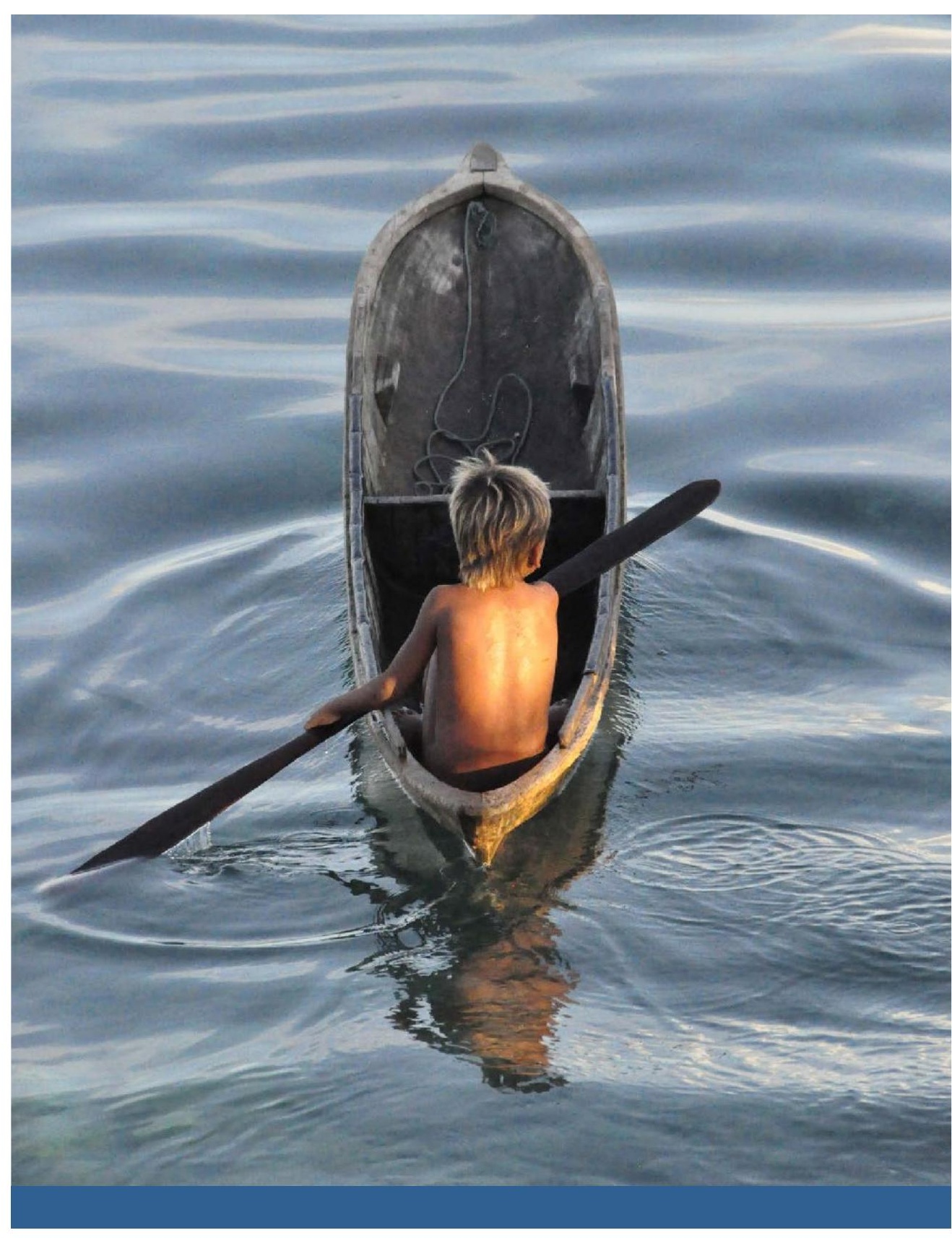

UNIÃO INTERNACIONAL PARA A CONSERVAÇÃO DA NATUREZA

SEDE MUNDIAL

Rue Mauverney 28

1196, Gland, Suiç̧a

Tel: +41229990000

Fax: +41229990002

www.iucn.org 